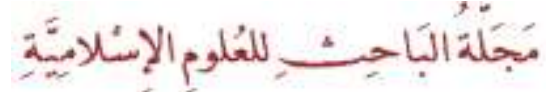

Researcher Journal For Islamic Sciences

Published by the College of Islamic Sciences at the University of Fallujah

ISSN p.p:2708-3993 / ISSN o.l: 2708-4000

Vol;1- Issue;1/ (2020-2021))

\title{
EXPECTATION AND ITS IMPACT ON \\ THE REALISM OF THE FATWA \\ ZAKAT ON WOMEN'S JEWELRY \\ BETWEEN THE PREFERABLE AND \\ UNPREFERABLE \\ AS A MODEL
}

Dr. Aiyad Khudhair Abbas/ University of Fallujah / College of Islamic

Sciences/dr.ayadkhdaer@uofallujah.edu.iq/ 07826528565

Dr. Eman Nazzal Muhisin / University of Fallujah / College of Islamic

Sciences / dr.emannazzal@uofallujah.edu.iq/ 07824955253

Abstract: The first topic (the concept of expectation and its elements, and its importance) included two demands, the first (the definition of expectation linguistically and idiomatically, and the reality of both expectation and expected), and the second (the pillars of expectation and its importance.

The second topic: Realism (realization of the criteria without the point of measurement. The first issue: the balance (public interests), The second issue: standards. The third issue: verification and standards .

$\Gamma \leqslant \Lambda$

Doi:10.37940/RJIS 2021.1.10 
The third topic: The effect of expectation on the realism of the fatwa, and the application of jurisprudence to reach the realism (Zakat on women's jewelry) between the preferable and unpreferable.

Then the conclusion, including the summary and some recommendations.

Keywords: (Expectation, Impact, Realism, Zakat Fatwa, Women's jewelry) 


\section{التوقع وأثره في واقعية الفتوى \\ زكاة حلي المرأة بين الراجح والمرجوح أنموذجاً}

/dr.ayadkhdaer@uofallujah.edu.iq / د. اياد خضير عباس / جامعة الفلوجة/كلية العلوم الاسلامية -vArqornoro

| dr.emannazzal@uofallujah.edu.iq / إيمان نزال محيسن العاني/ الانتساب: (جامعة - كلية) -VAr

الملتخص:

في صفحات هذا البحث: (الثوقع وأثره على واقعية الفتوى، زكاة حلي المرأة بين الراجح والمرجوح، أنموذجاً).

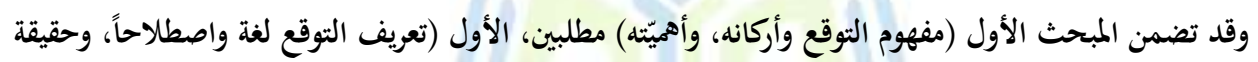

كل من التوقع والمتوقّع)، والثاني (أركان التوقع، وأهميّه).

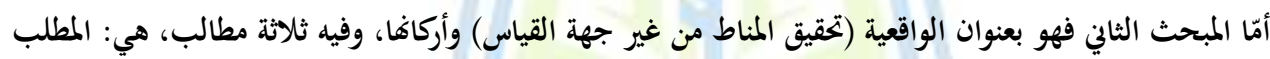

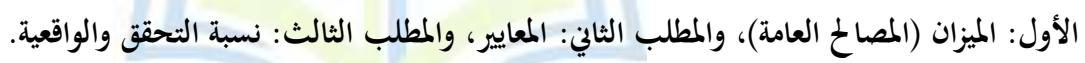

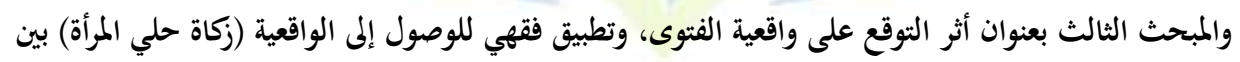

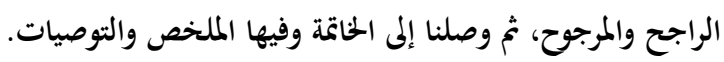
الكلمات المفتاحية: (التوقع، الأثر، واقعية الفتوى، زكاة حلي المرأة، الراجح والمرجوح).

ro. 


\section{التوقع وأثره في واقعية الفتوى \\ زكاة حلي المرأة بين الراجح والمرجوح أنموذجاً \\ د. اياد خضير عباس/ د. إيمان نزال محيسن العاني \\ جامعة الفلوجة / كلية العلوم الإسلامية}

المقدمة

أنَّ شريعتنا تتكون من كليات وجزئيات؛ أمّا الكليات فهي عامة كفيلة بالحفاظ على الدين، النفس، المال،

النسل، وكذلك العقل.

كما من المعروف أنّ من الأهمية بيان أنّ الفقه حلّ ومنهج وليس مشكلة، ومن أجل بيان تلك الأهمية يقوم

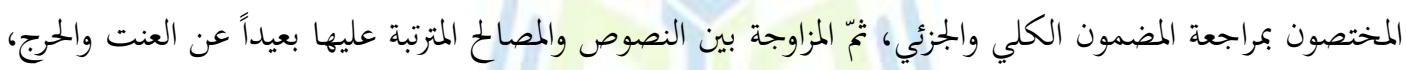
تُّ إيجاد الميزان المعنوي للضرورات وتقديرها في محاولة للمقاربة والسداد. فترتبت الرخص ضمن ضوابط وقواعد اعتمدها الجيل الأول في الفتوى، وبادروا إلى العمل بالمشوروة ولمعادية والفقه الجماعي

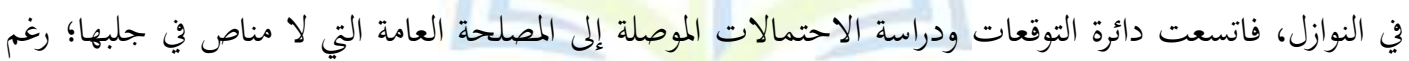

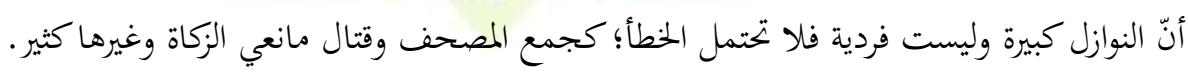

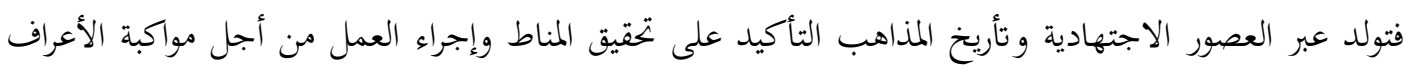
والأزمان وطروء الضرورات والحاجات والمصالح المتجددة.

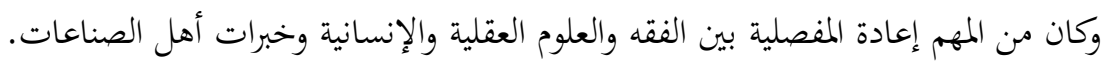

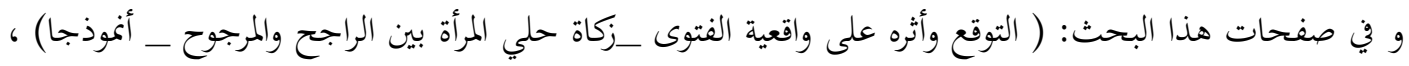

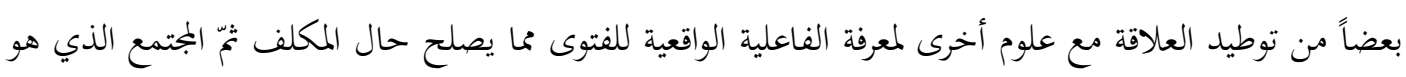


أمّا منهج البحث فهو التعريف بالألفاظ (التوقع)، (الواقعية)،وبحث نسبة تحقق واقعية الحكم إذا دخل التوقع عليه،

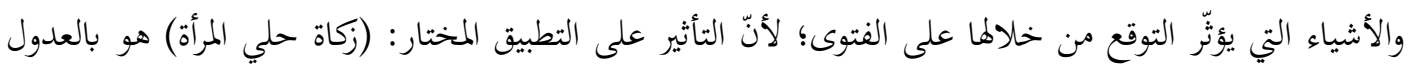

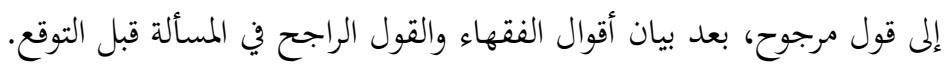

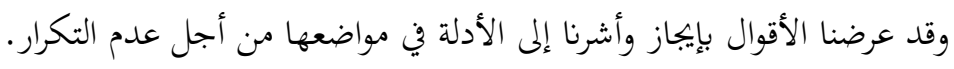

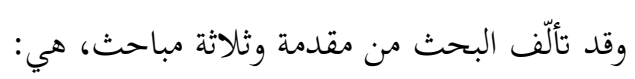

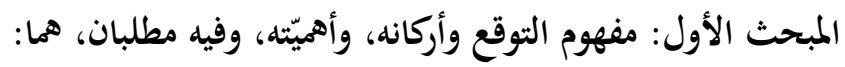

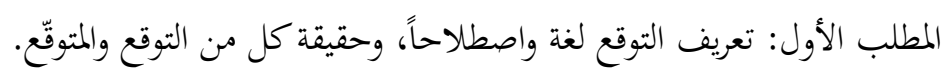

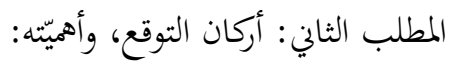

المبحث الثاني: الواقعية (تحقيق المناط من غير جهة القياس) وأركانها، وفيه ثلاثة مطالب، هي:

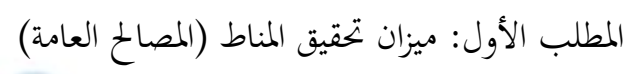
المطلب الثاني: معايير التحقيق (العقل). المطلب الثالث: نسبة التحقق (الواقعية). المبحث الثالث: أثر التوقع في واقعية الفتوى، وتطبيقه الفقهي للوصول إلى الواقعية (زكاة حلي المرأة) بين الراجح والمرجوح.

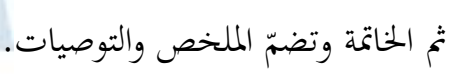
هذا ونسأل الله العظيم أن يعفو عن زلاتنا وهفواتنا؛ فعذرنا أن الكمال لله وحده، وصلى الله وسلم على نبينا مُحمّحم وعلى آله وصحبه أجمعين. 


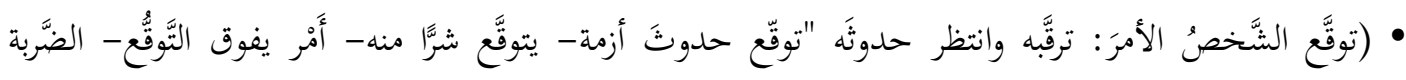

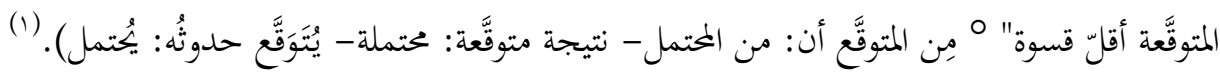

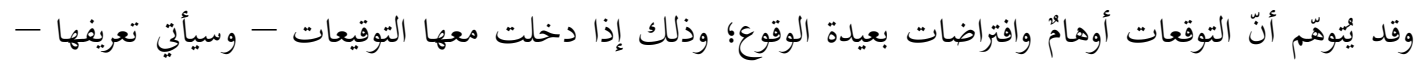

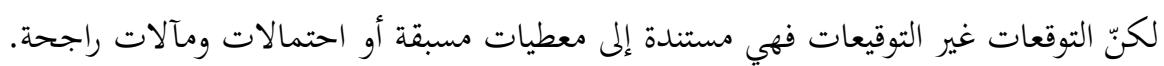

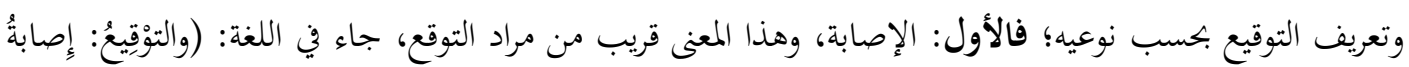

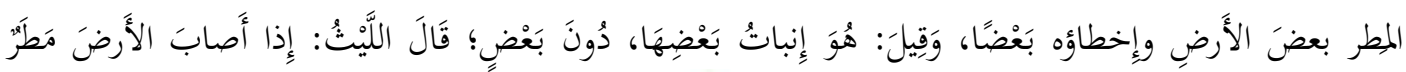

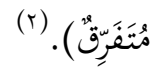
والثاني: الرمي؛ وبدخل فيه الظنّ والهوى والوهم فني اللغة له معنى التظّيّ والوهم أي الق ظلّّك على الشيء، وهذا

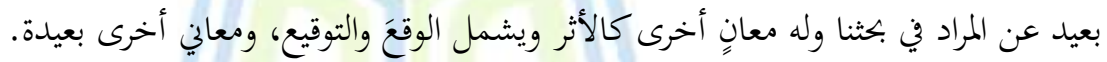

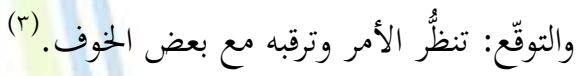

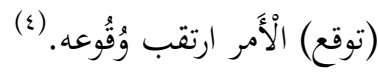

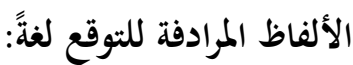
هناك ألفاظ بتجمع مع التوقع في معناه اللغوي وتوضحه، ومنها:

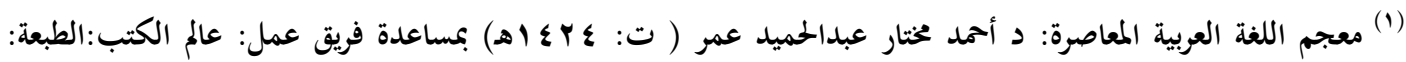
الأولى، 9 \& أه-

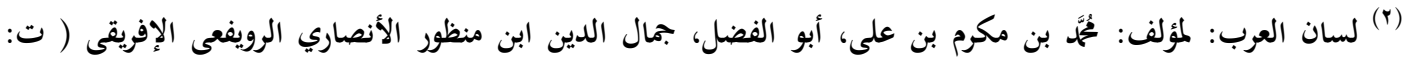
| (ז) ( (ألمعجم الوسيط: مجمع اللغة العربية بالقاهرة، (إبراهيم مصطفى / أحمد الزيات / حامد عبد القادر / مُحََّ النجار): دار الدعوة: $.1 \cdot 0 \cdot / r$ ror 
- الترصد: من الرصد والرصد: كل شيء أمامك. فالرَمَدُ مايكبس به، وقيل الطريق والممر، وأيضاً هو اسم

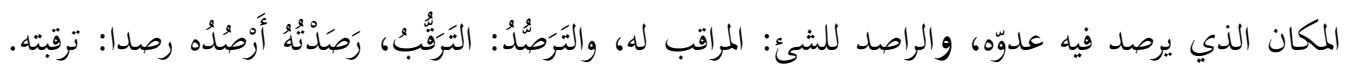

$$
\text { وأرصدت له: أعددت له "). }
$$

- الترقّب: الانتظار، وأرقبه داراً أي أعطاه إياها وقال: هي للباقي منّا، وهي من المراقة؛ لأن كل منهما

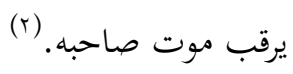

ثانياً: التوقع في الاصطلاح: قال ابن بيه:

(التوقع هو مصطلح جديد وإن كان حديثاً بالنوع قديماً بالجنس، فالجمال الذي يغطيه فقه التوقع هو بحال تغطية

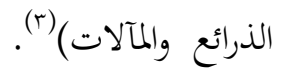

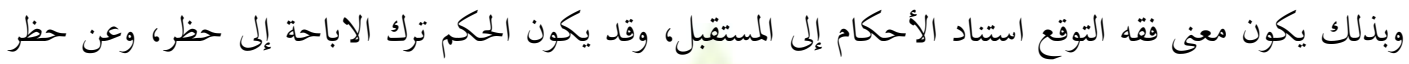

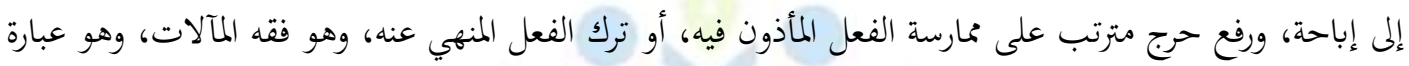

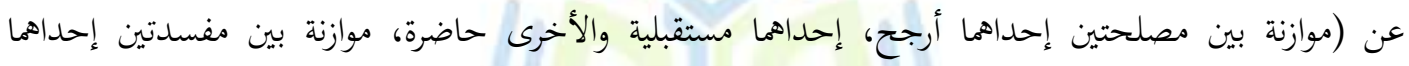

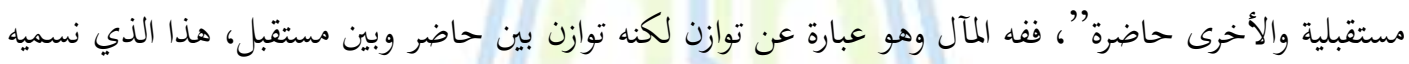

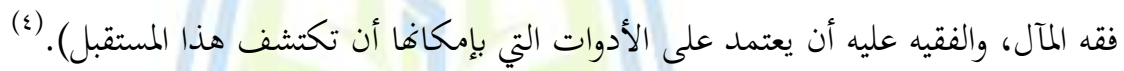

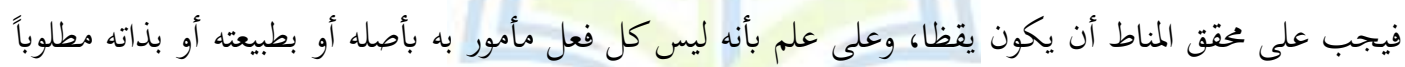

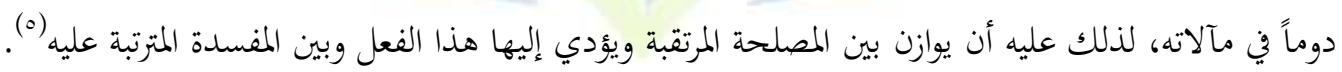

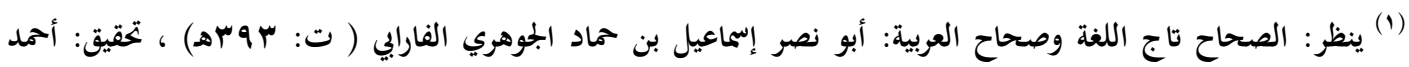

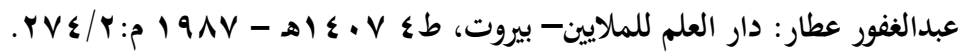

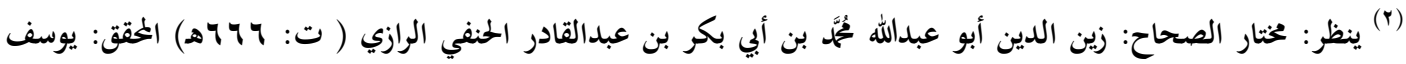

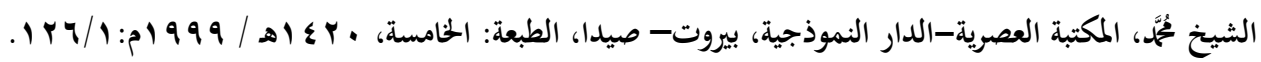

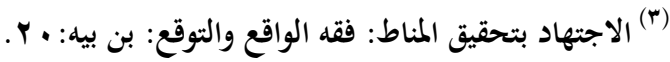

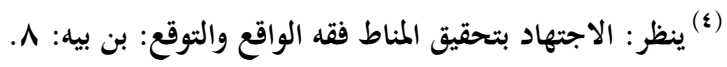
(1) (1) (المصدر نفسه.

ros 
حقيقة التوقّع والمثتوقع: بعد تعريف التوقع ومعرفة ماهيّّه لغةً واصطلاحاً بأنه عملية نظر لمتخصِّص في حال وواقع

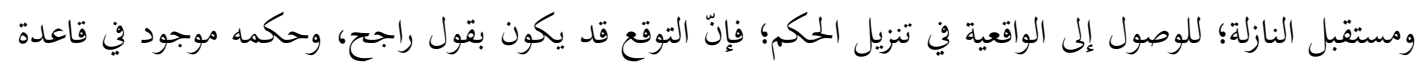
كلية وهذا هو الأصل؛ لكن أحياناً يتخذ التوقع صوراً أخرى، منها: سدّ ذريعة: وذلك إذا توقّع مفسدة محققة وقصد دروها. " مصلحة مسترسلة: وذلك إذا توقع مصلحة وقصد جلبها. (')

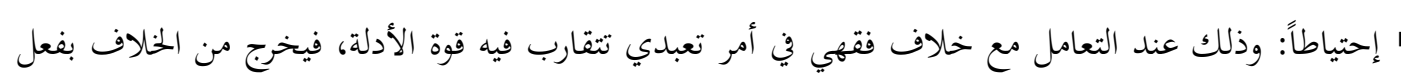

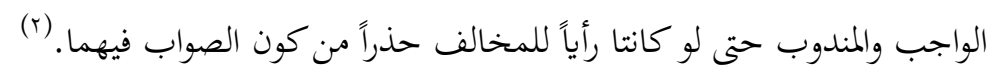
" الورع: وذلك عند تغليب حكم الحرام على الاباحة عند الترجيح بين الادلة(r). فكل ذلك يدخل فيه النظر والترقب والحذر من شيء بحيث يكون مرجحاً لتنزيل الحكم وليس تفريطاً ولا تنازلاً بل هو الوصول إلى الواقعية حالاً ومستقبلاً.

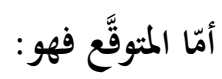
المآل المجسد في ذهن محقق المناط؛ فيرى بين ناظريه النتيجة المرتقبة من فتواه كواقع حال بعد معرفة خارطة ذلك

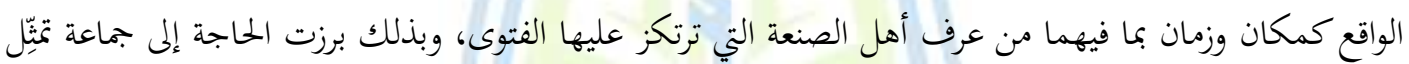

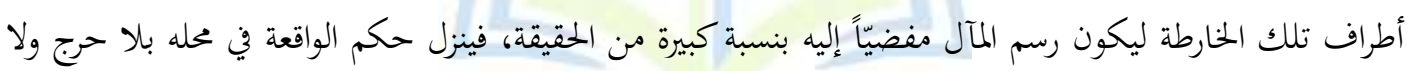

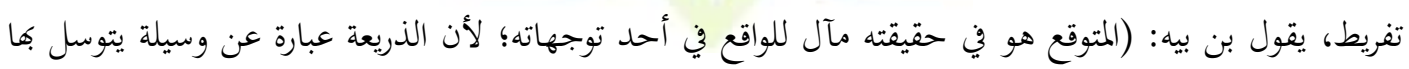

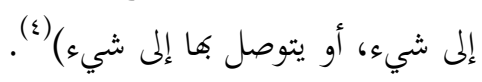

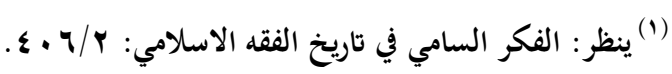

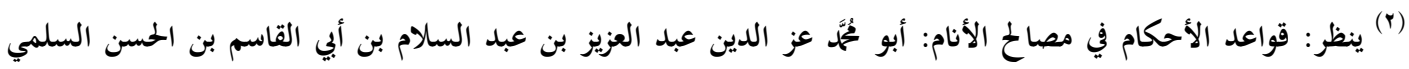

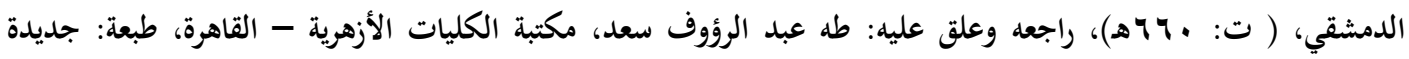

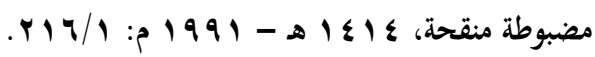

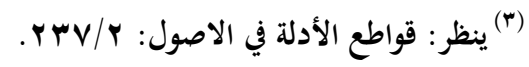

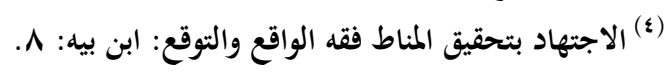

roo 
وبذلك نستطيع القول بأنَّ التوقع يبتعد عن الوهم والخيال والإفتراضية لما فيه من قوة الإحتمال ورجوح المصالح

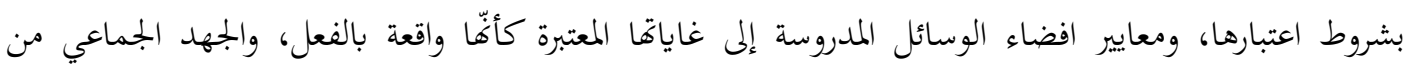
الاختصاصات المختلفة التي تجمع أطراف المفتى به.

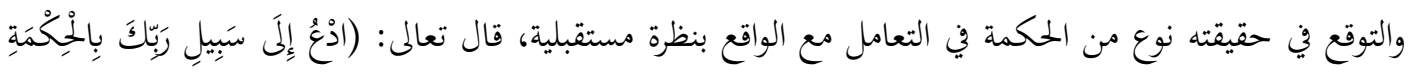

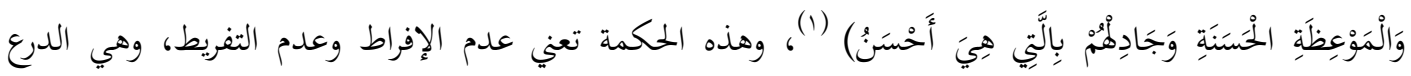
الحصين للتوقي من المزالق والأخطاء في الفتوى.

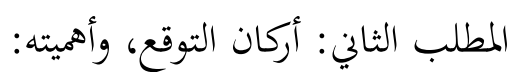
بما أنّ للتوقع أبعاد لغوية واجتماعية معاكسة تماماً للمراد هنا؛ فلا بدّ من بيان بعض الأركان -إذا صِّ التعبير-

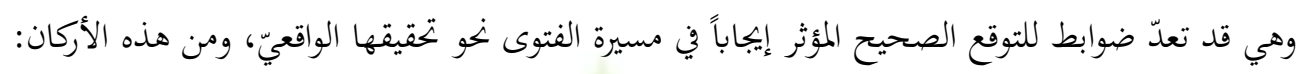

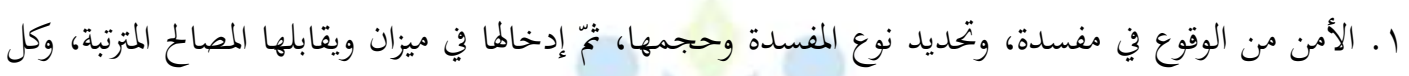

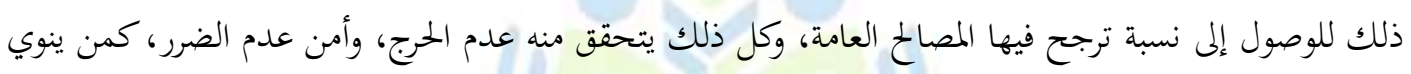

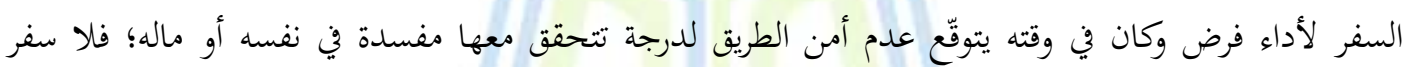
عليه ويدخل في الرخصة لعدم الاستطاعة (r).

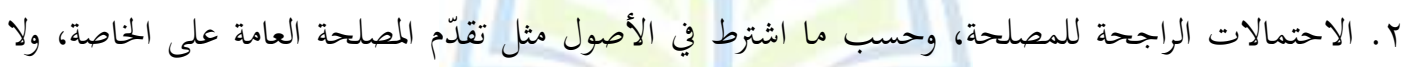

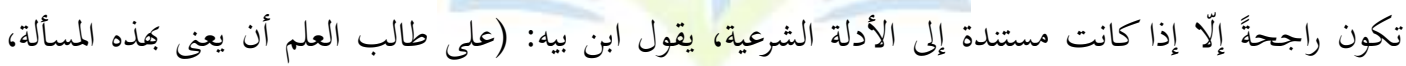

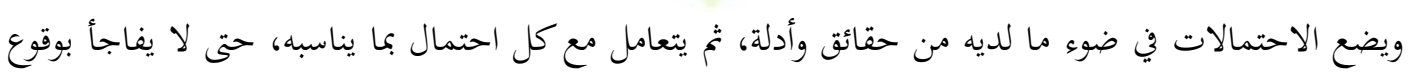

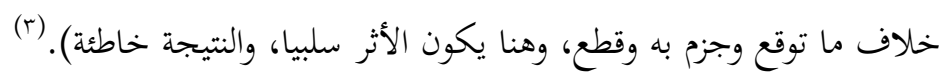

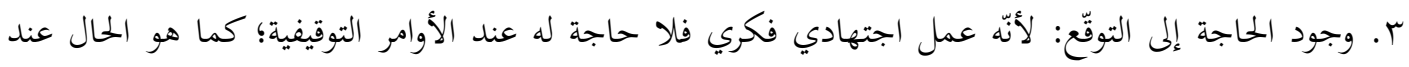

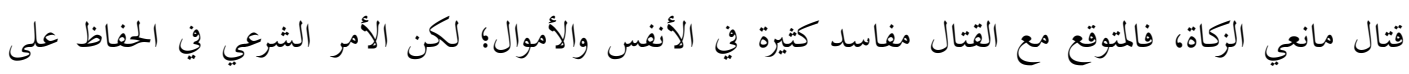

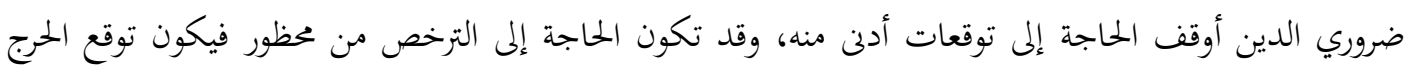

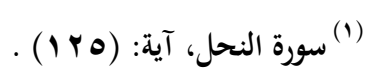

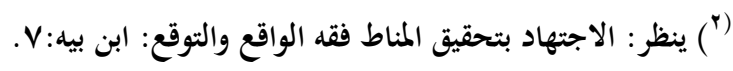

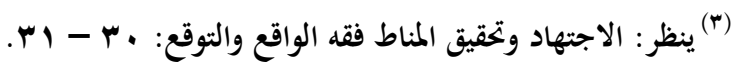


وموازنة المصالح حاضراً؛ كحاجة المرأة إلى الخروج و العمل، وقد يصاحب الحكم الشروط والضوابط بما يضمن رفع

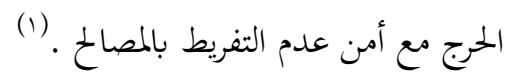

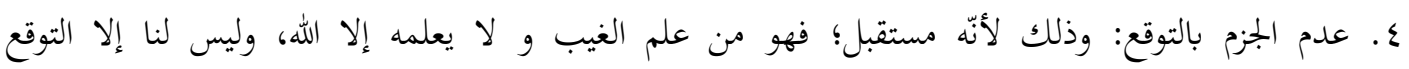

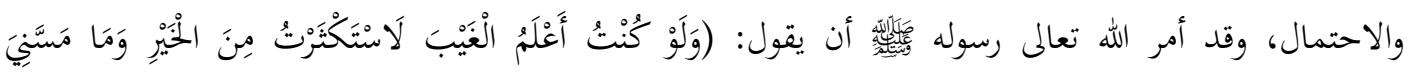

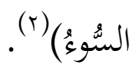
ه. الجها الجماعي (المشورة): إنّ أهمية هذا الركن تأتي من كون النازلة فرعية ولها أطراف متعددة أغلبها مستقبلية؛

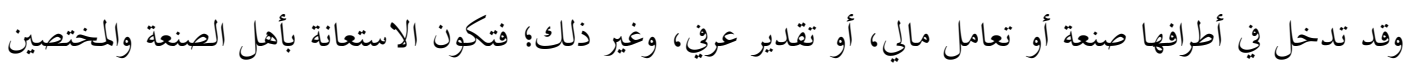

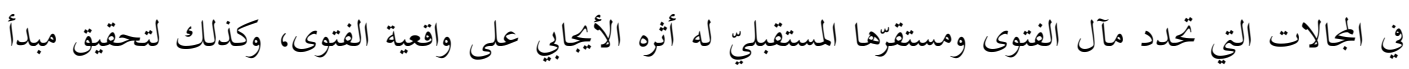

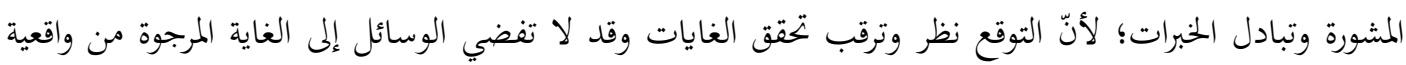
وتيسير في العمل بالفتوى الناتجة (r)

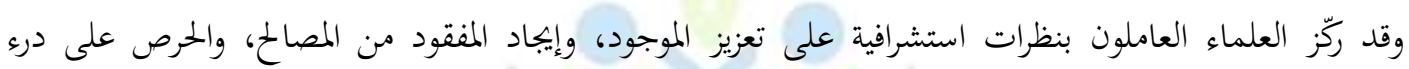

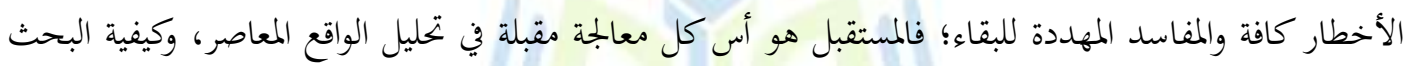

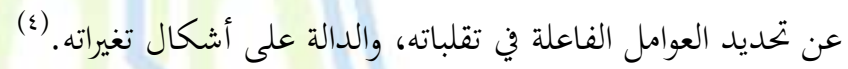
أهمية التوقع: - من فين لقد فطن العلماء إلى أهمية النظرة المستقبلية للعمل بالفتوى؛ فكان من بتديد بعض مذاهبهم وضع قاعدة (إجراء

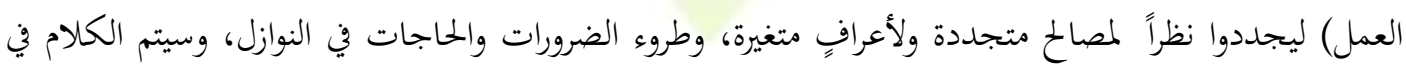

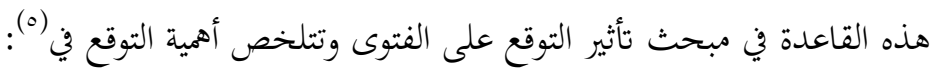

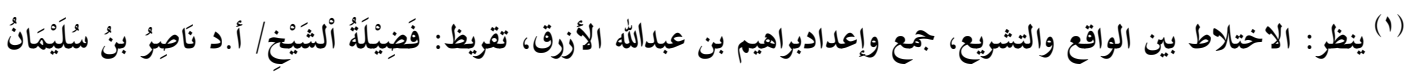

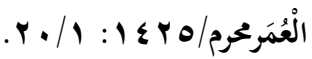

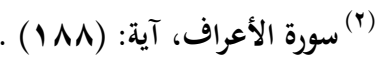

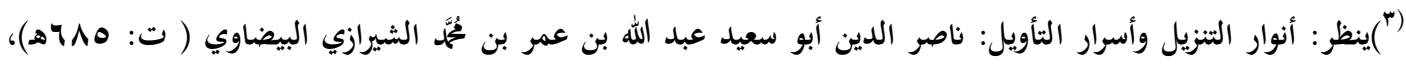

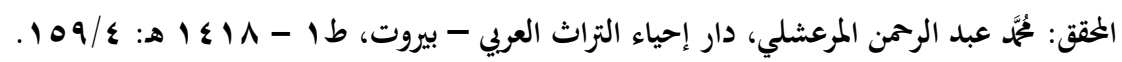

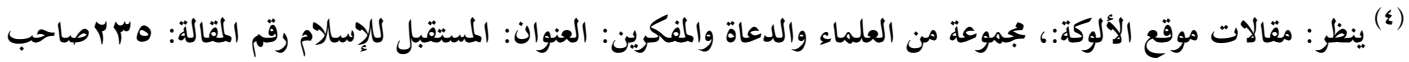

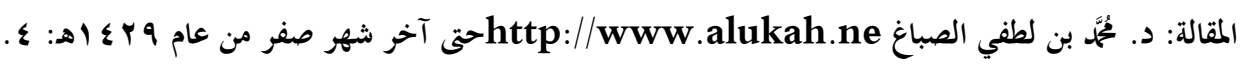

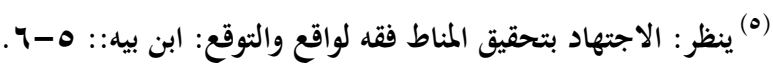

rov 
ץ- توسيع دائرة الاجتهاد، وترشيح الكليات وترجيحها على النظر الجزئي.

$$
\begin{aligned}
& \text { r- تقليص الأضرار. } \\
& \text { ع - - - التيسير وعدم الحرج. } \\
& \text { ه- - - التواصل بين الواقع وبين الأحكام. } \\
& \text { T- الإنضباط في الاستباط. }
\end{aligned}
$$

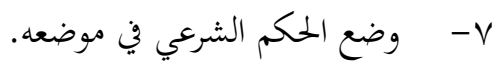

$$
\begin{aligned}
& \text { م- - مبذ الإطلاق والعمل بالتقييد والتخصيص. } \\
& \text { 9- تقديم الحلول السليمة المناسبة للعصر. } \\
& \text { • 1- تحقيق الشمول والعموم للشريعة من خلال ربط الجزئيات بالكليات. }
\end{aligned}
$$


بداية يجب التعريف ببعض الألفاظ لغة واصطلاحاً، ومعرفة صورها، وتحديد موقع التوقع بالنسبة إليها.

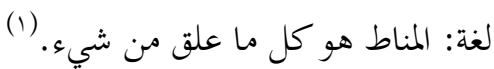

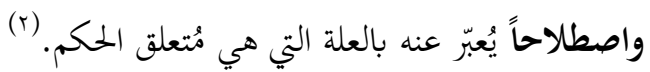
وتحقيق المناط هو النوع الاجتهادي الذي لا ينقطع، وله صور هي مراحل لنهي للوصول إلى واقعية الفتوى المنشودة، والصور هي: وتكيق - الكشف عن العلة المعتبرة.

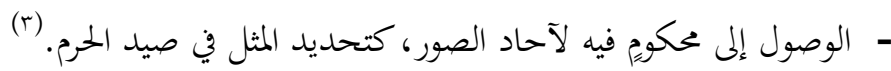
- الكشف عن الحكم في مورده من نص أو اجماع وربطه بمحال تطبيقه، قال الشاطبي (رمه الله): (الشريعة لم

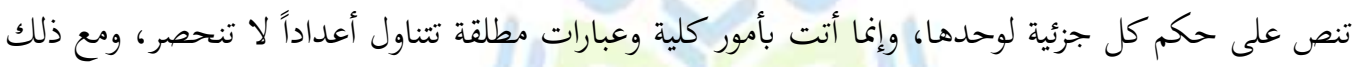
فلكل معيّن خصوصية ليست في غيره ولو في نفس التعيين، وليس ما به الامتياز معتبراً في الحكم باطلاق، ولا هو طردي باطلاق، بل ذلك منقسمُ إلى الضربين، وبينهما قسمٌ ثالث يأخذ بجهة من الطرفين، فلا يبقى صورة

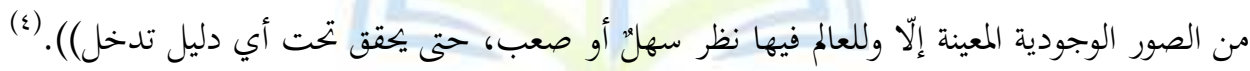

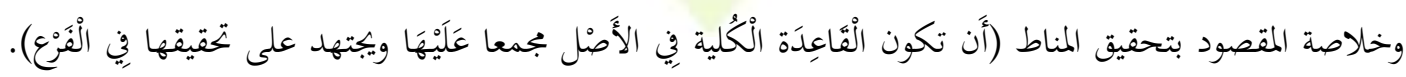

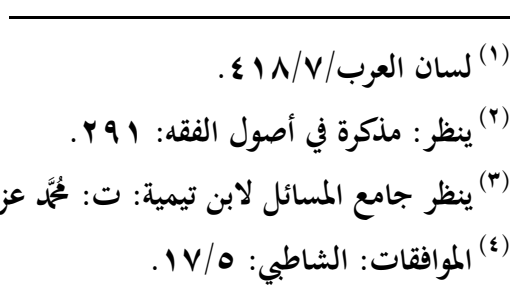

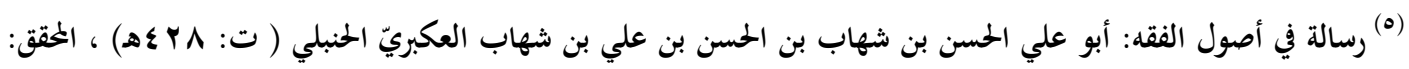
roq

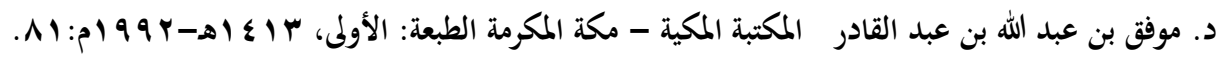




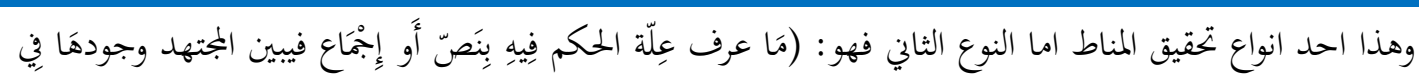

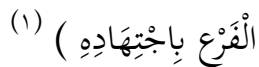
ونقصد بتحقيق المناط في غير جهة القياس في بحثنا النوع الأول وهو اندراج الصور والأنواع الفرعية تحت القاعدة

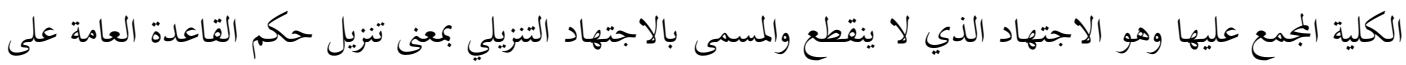

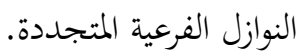
وقد أطلق عليه الشاطبي (رحمه الله): المبلح، ويطلق عليه أيضاً فقه الواقع؛ أي اسقاط الحكم على واقعته (r).

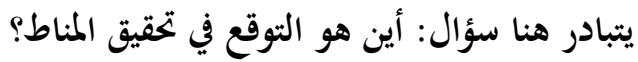
في حالة العودة إلى تعاريف الاجتهاد التطبيقي وفقه التنزيل نجد أنّ الأول هو النظر من ذئي ذي ملكة في في معرفة المنوط

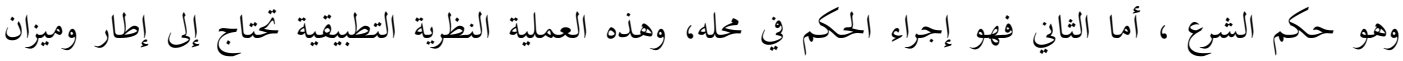

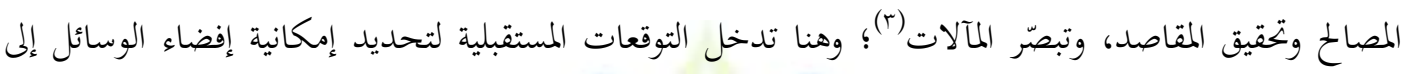
غاياتما.

$$
\text { المطلب الأول: ميزان تحقيق المناط (المصالح العامة) }
$$

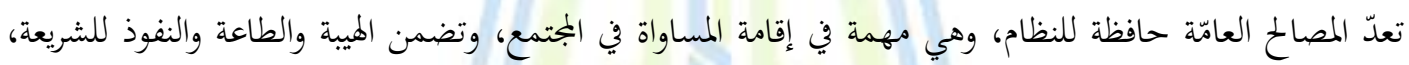

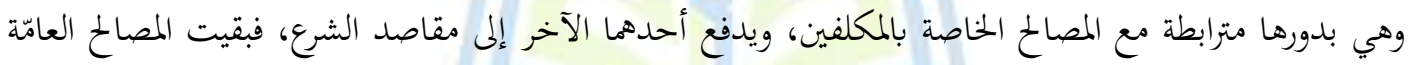

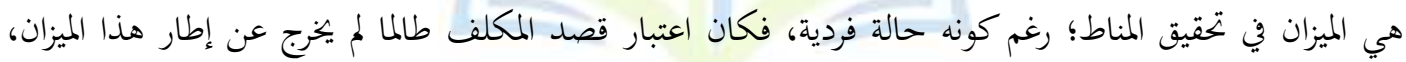

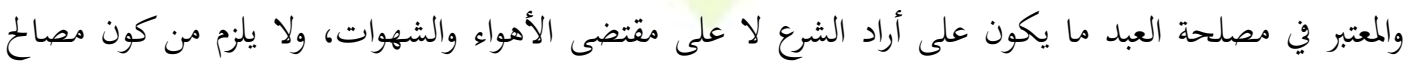

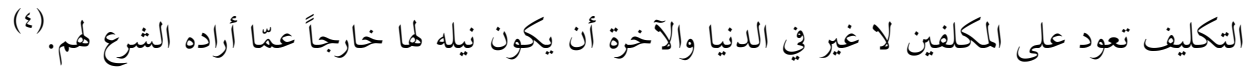

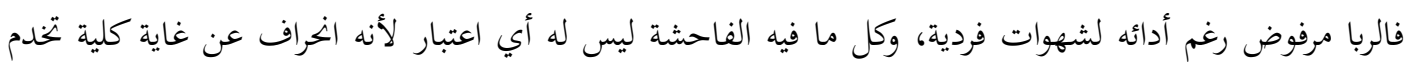
عام الدين أو النفس أو المال أو العرض أو النّسل.

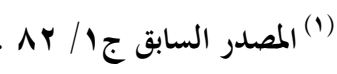

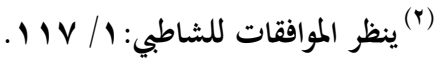

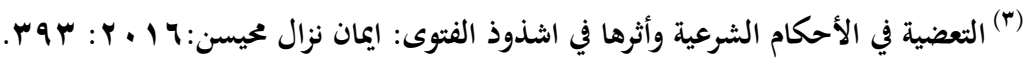

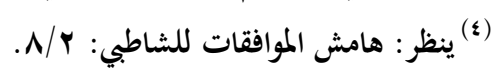

พч. 
فالواقعية في عدول العلماء إلى قوت البلد في زكاة الفطر كان تحت ميزان سدّ خلة الفقراء يوم العيد وبالنظر إلى عدم

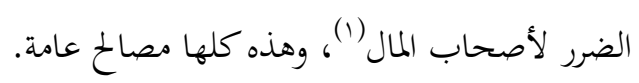

وتبقى المقاصد الفردية اقل رتبة من العامة، وكذلك قد تطرأ عليها تغييرات كالرخصة عند الإكراه في كلمة الكفر، الكاب،

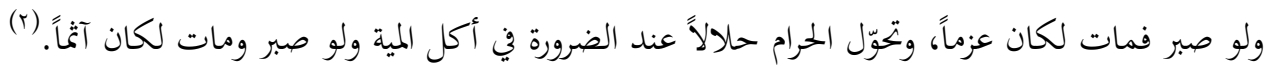

$$
\text { المطلب الثاني: معايير التحقيق (العقل): }
$$

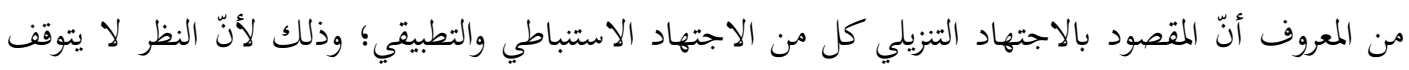

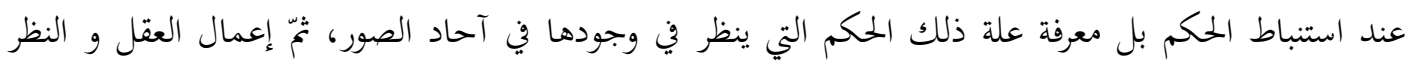

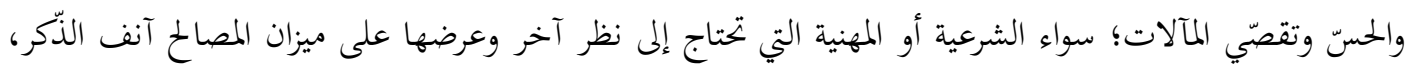

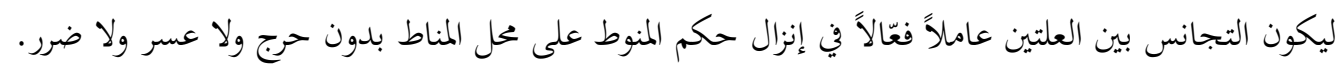

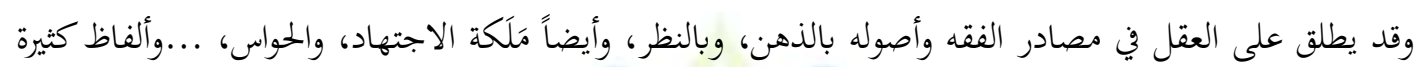

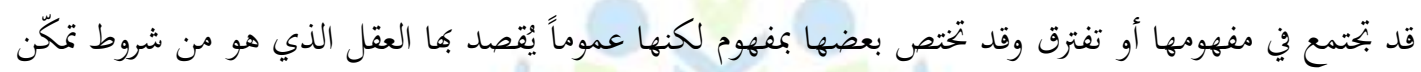
المجتهد؛ كذلك كان من أسباب تقسيم المجتهدين إلى مراتب: أعلاها: العالم بالمعارف وله مَكَكة الاجتهاد. تئّ: الحافظ للمعارف وله مَأكَة الاجتهاد.

وأدناها: المفتقر للمعارف لكنه ينظر كيف عمل أهل المعارف في المسألة. (r)

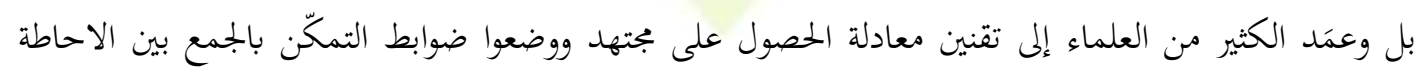

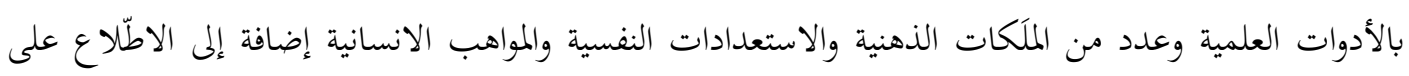

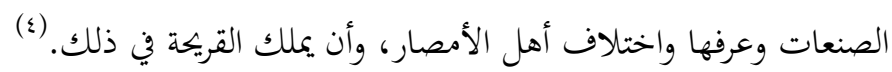

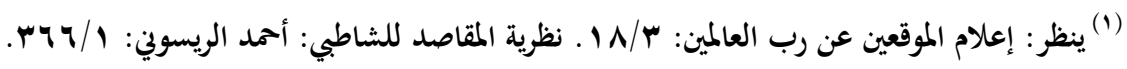

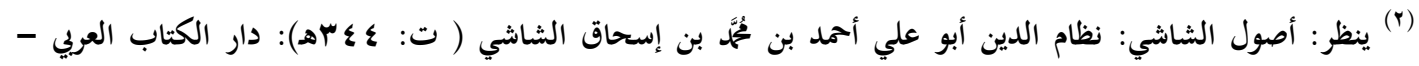

$$
\begin{aligned}
& \text { بيروت: / هNr/ المستصفى: VN/1. }
\end{aligned}
$$

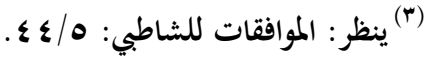

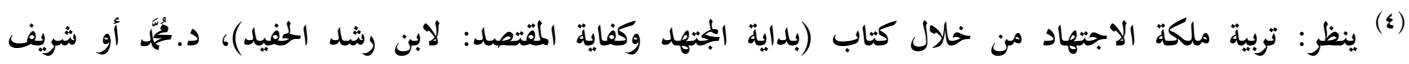
MT) 


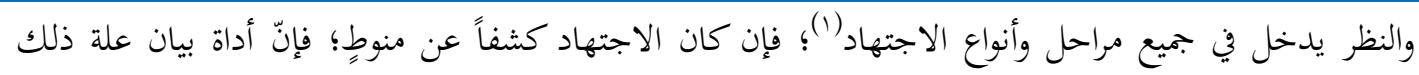

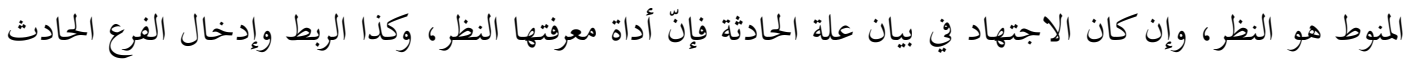

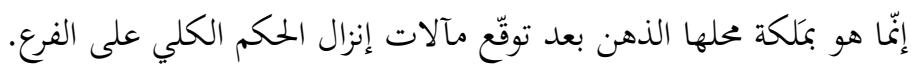
المطلب الثالث: نسبة التحقق (الواقعية): الوسائل مآلات بحد ذاتما، إضافة إلى كوها مسالك تؤدي إلى غائات التهات أكبر هي مآلات أيضاً لكنها مصالح عامة

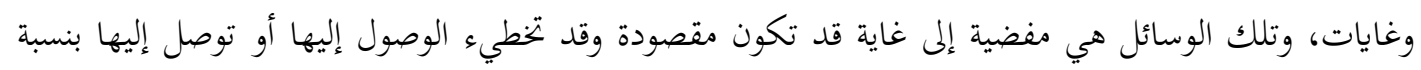

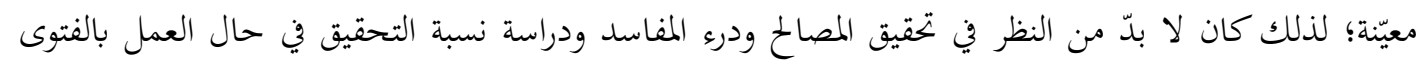
وكل ذلك يكون قبل العمل بها بل وقبل إصدارها. وهذا هو التوقع الذي يؤدي إلى واقعية الفتوى؛ حيث لا يكلي العي تصوّر النتيجة المتأخرة دون النظر إلى جميع مراحل

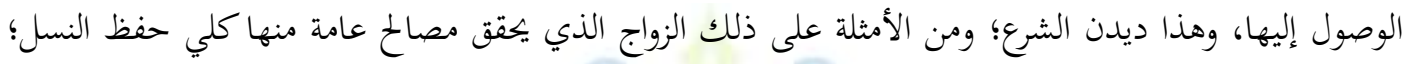

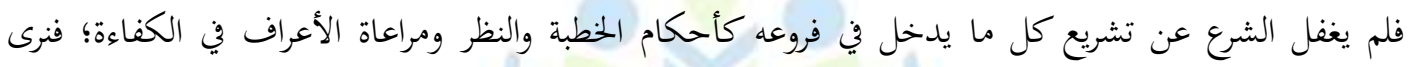

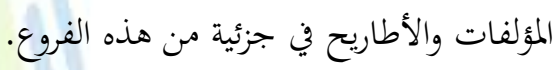

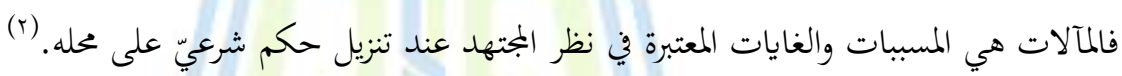

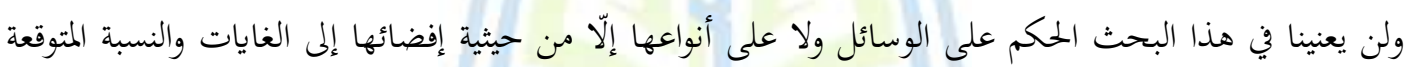

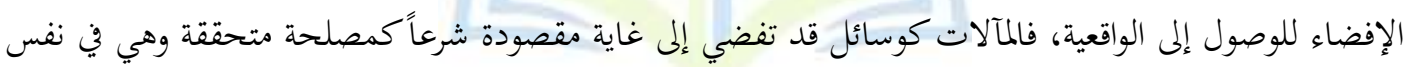

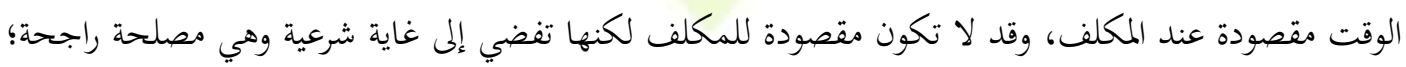
فالنظر إلى المصلحة المتحققة أوالراجحة يجعل تلك الوفل الوسيلة مطلوبة لا تؤول إلى حرام؛ كتشريح الجثث في الكليات

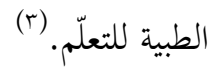
أمّا إذا لم تفض إلى مقصد شرعي فهي تؤول إلى مفسدة متحققة؛ فنحكم عليها بعدم القبول وهي الوسائل

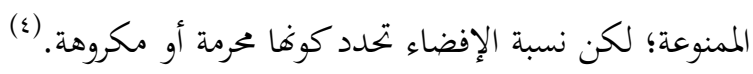

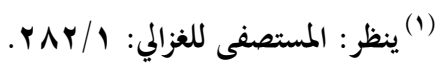

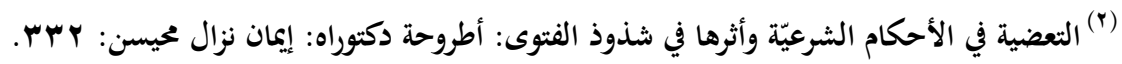

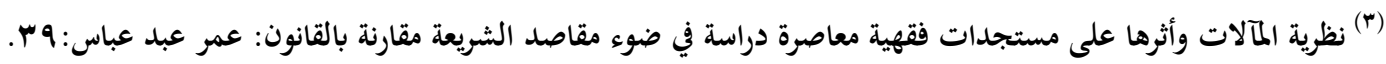

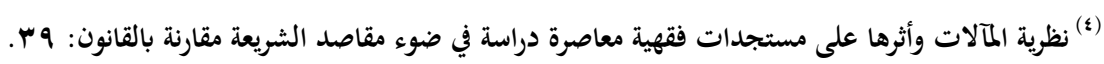

rTr 
المبحث الثالث: أثر التوقع على واقعية الفتوى، وتطبيق فقهي للوصول إلى الواقعية (زكاة حلي

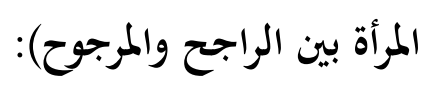

قد يبدو تأثير التوقع هيناً على واقعية الفتوى؛ وذلك لأنّ غير المتخصصين يرون النظرة المستقبلية بعيدة وتدخل فيها

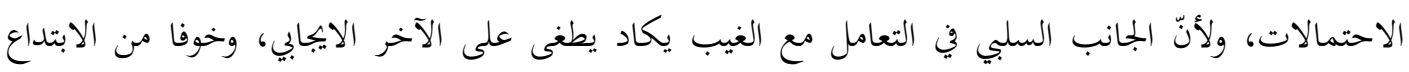

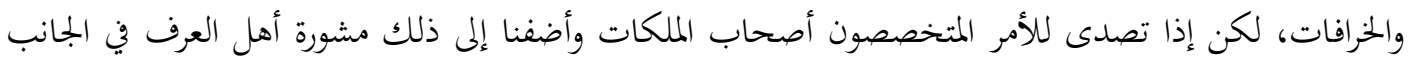

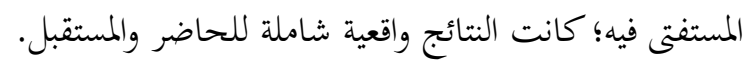
ويكمن التأثير للتوقع في أشياء كثيرة؛ منها: 1- الرخصة: وهي ما يستباح بعذر مع قيام المخرم، وقد تدخل في الأداء دون التبديل للضرورة، كما قد يكون إنداء

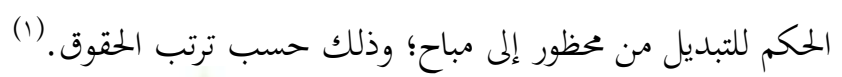

فالمكلف عند الرخصة بين عزيمة ورخصة وذلك لأن ما جاز فعله إما أن يكون جائزاً مع قيام المقتضى للحظر ؛ وهذا

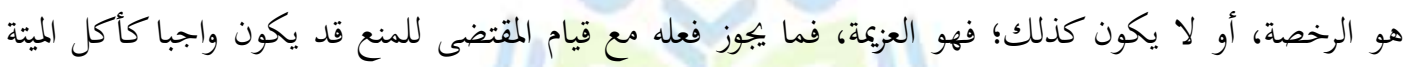

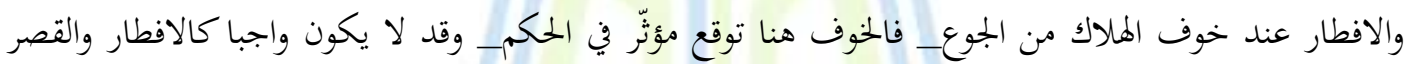

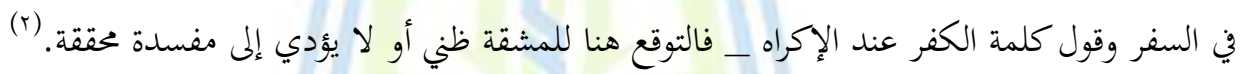

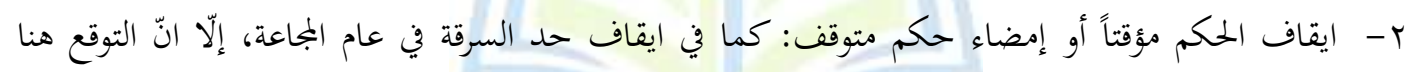
أضعف من وجود المانع للحكم.

(1) ينظر : أصول البزدوي - كنز الوصول الى معرفة الأصول: أبو الحسن علي بن مئمَّ بن الحسين بن عبد الكريم، فخر الإسلام

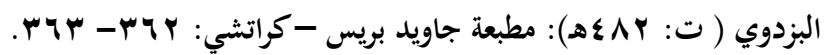

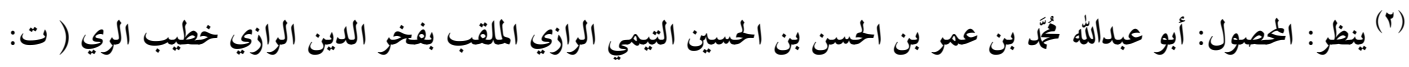

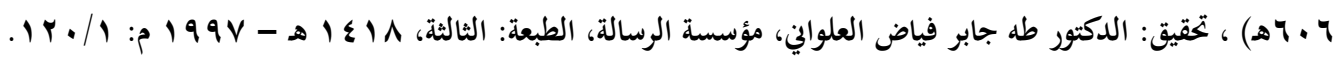
זד 
r- العدول إلى قول مرجوح: يعتمد التوقع على غلبة الظنّ والاحتمالات الراجحة، وقد يعضد دليلان متعارضان

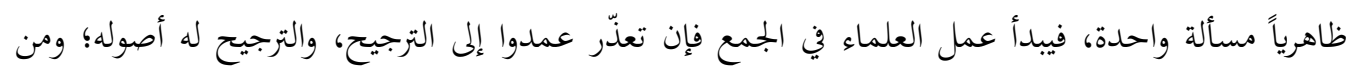

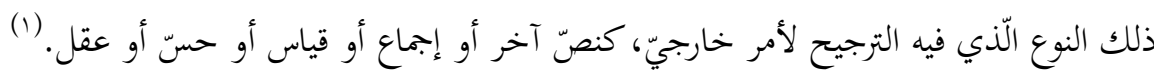

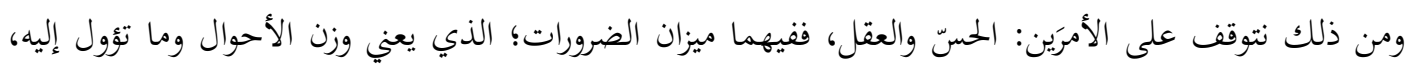

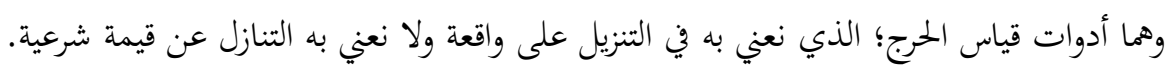

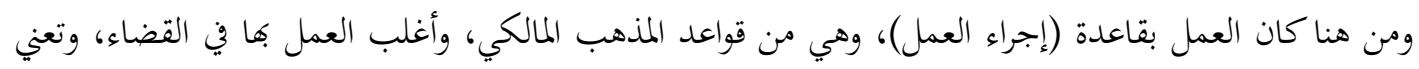

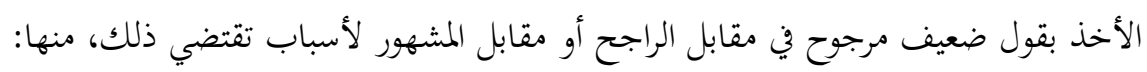

$$
\text { - }
$$

وهذا العمل يبقى بشكل مؤقت كالرخصة وحسب أحوال معيّة؛؛ لأفّم يرون ذلك أدعى إلى تحقيق مقصد الشرع

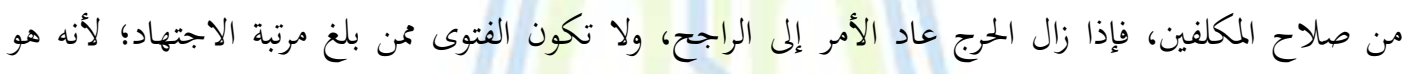

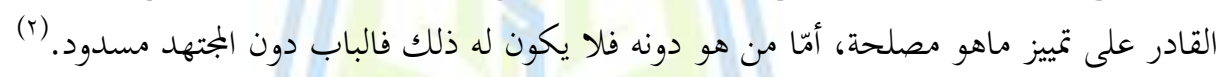

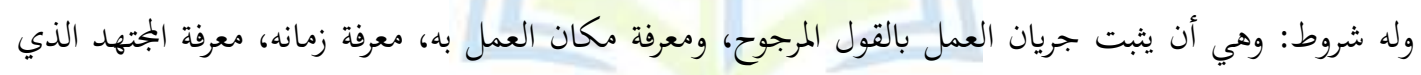

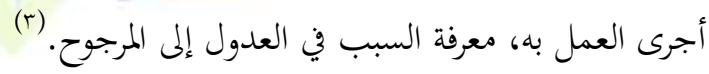

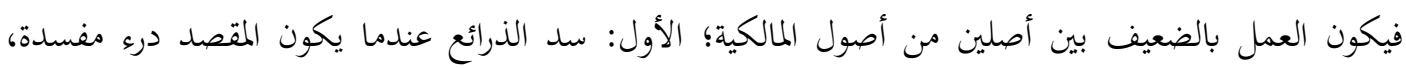

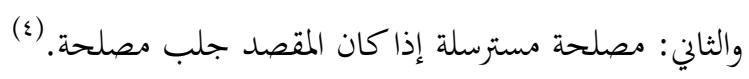

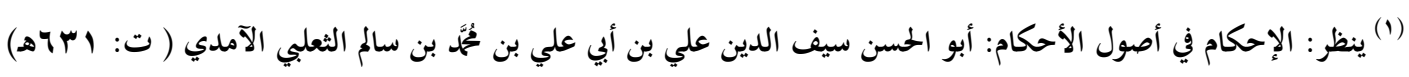

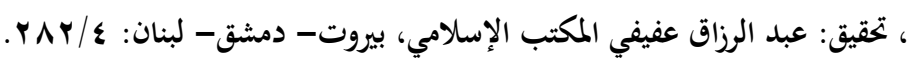

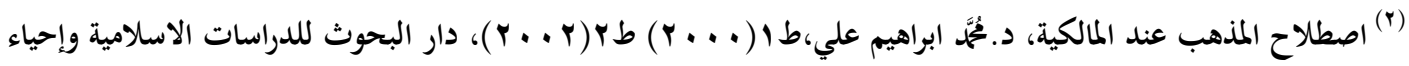

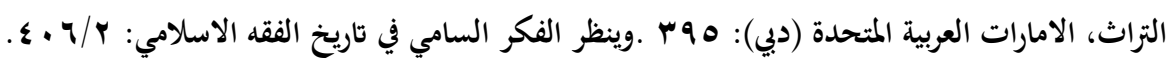

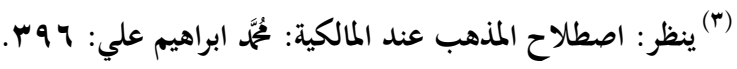

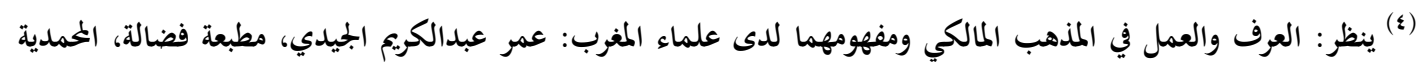

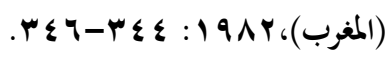
Tฯร 


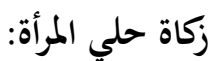

إنَّ الخلاف في زكاة الحلي مشهور، وهو في كتب الفقه لجميع المذاهب؛ لكن باختصار نوعاً ما أنقل أقوال المذاهب

أولاً: فصّّل الحنفية فحدد أبو حنيفة بوجوب الزكاة في الحلي حدّاً أدنى للحليّ الّذي بحب فيه الزكاة، وهو مايعادل

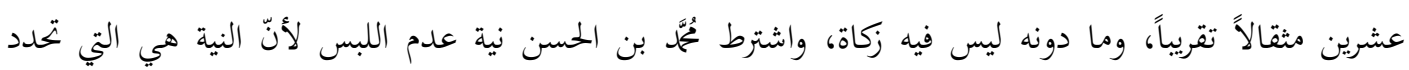
(1) العبادات. (1) ثانياً: المالكية قسّموا العلة في الحلي إلى جوهر يفيد النماء بحب فيه الزكاة إجماعاً، وأخرى بالصياغة صورة تسقط فئان

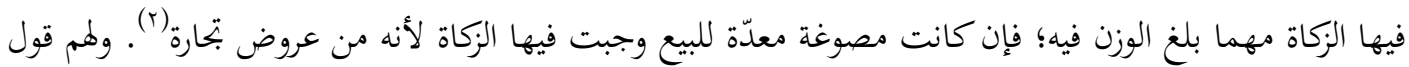

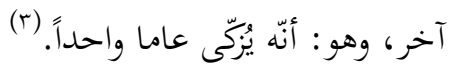

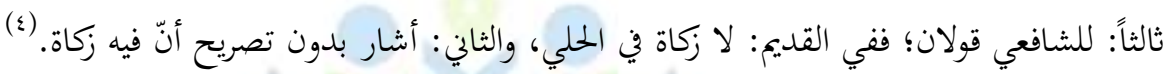

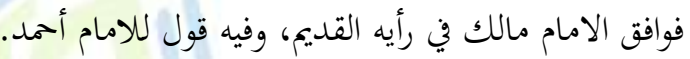

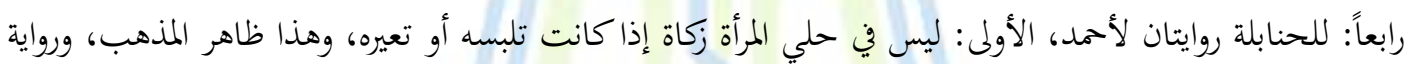

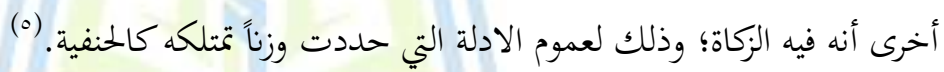

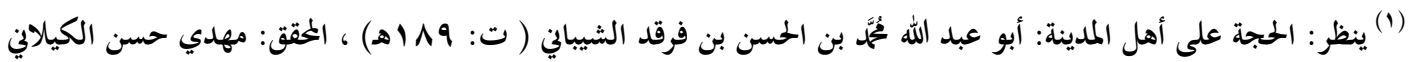

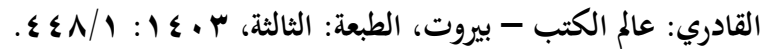

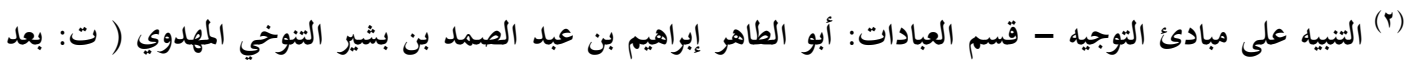

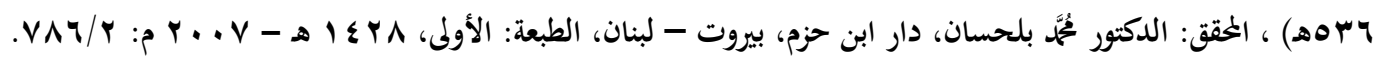

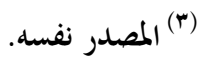

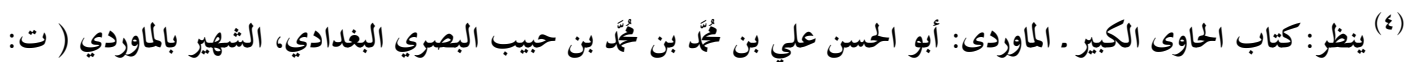

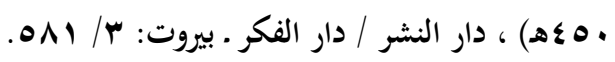

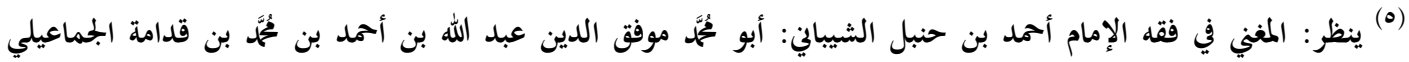

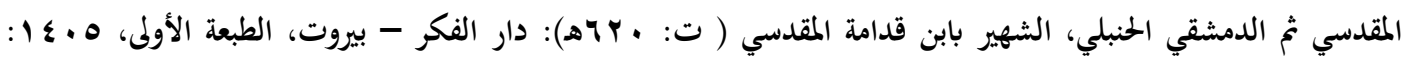
$.7 \cdot r / Y$

พา0 


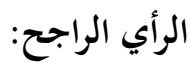

نقل أغلب العلماء ترجيحهم بعدم وجوب الزكاة في حلي المرأة، وحسب التقسيمات الآتية: ا- الذهب والفضة المصوغ للزينة واللبس مهما بلغت قيمته؛ بشرط إباحة استعماله، فقليل الحلي عندهم وكثيره سواء في الزكاة؛ لأن الشرع أباح التحلي مطلقا من غير تقييد، فلا يجوز تقييده بالرأي.

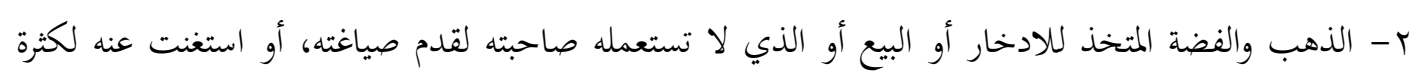

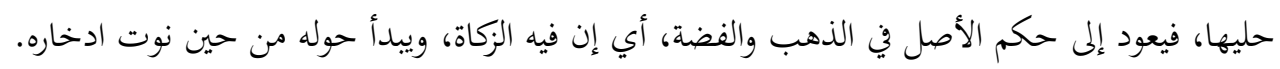

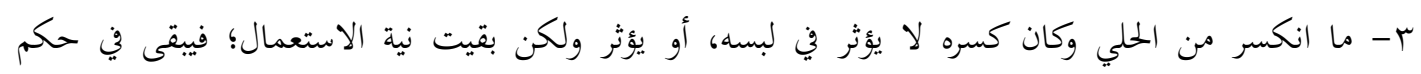
المستعمل لبقاء نية اللبس فيه، أي لا زكاة فيه.

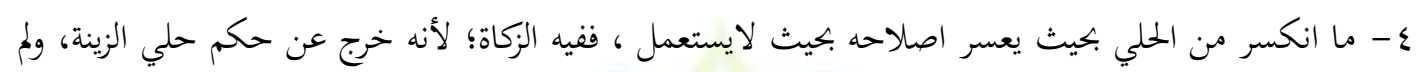
تبق فيه نية الاستعمال، وحوله يبدأ من حين انكساره.

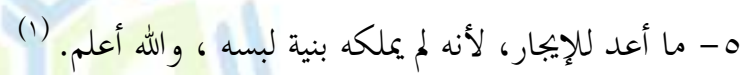

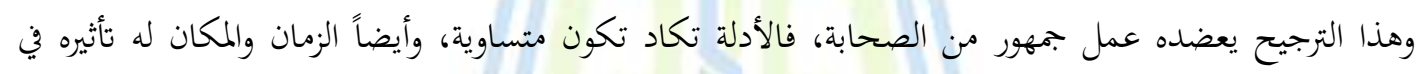

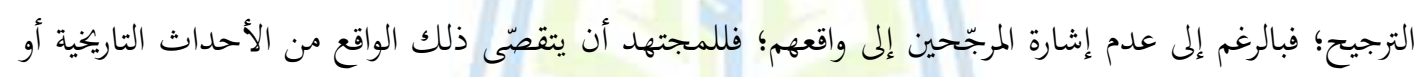

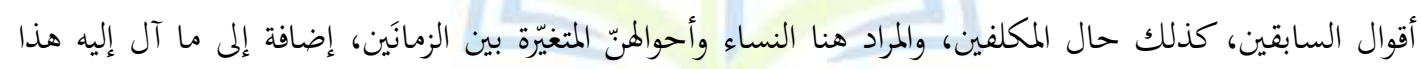
الترجيح والمصالح المستجدّة. فعند النظر إلى المسألة نجد أثر التوقع على زكاة حلي المرأة من خلال:

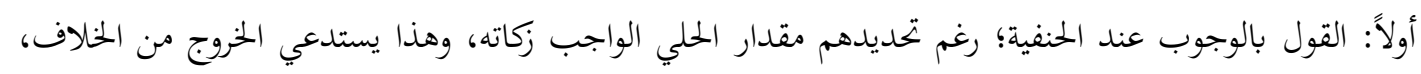
والتوقع هنا هو سدّ ذريعة الذّّ حال عدم فعل الواجب.

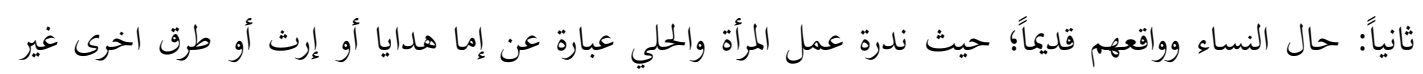

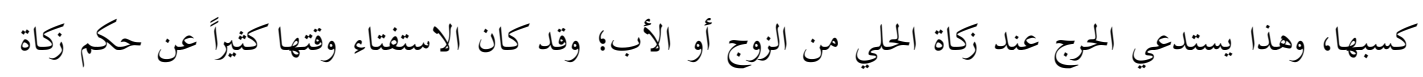

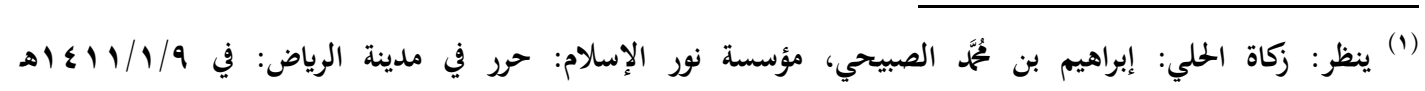
www.islamlight.net

พัน 
الزوج حلي زوجته، أمّا في زمننا فقد استولت المرأة على فرص العمل، وأصبحت حليها عبارة عن ما زاد من راتبها

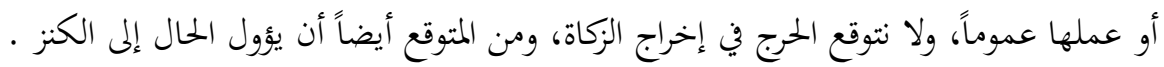

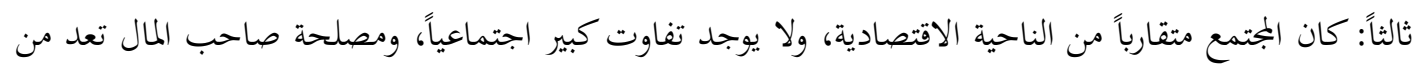

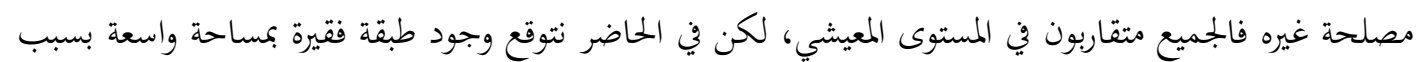
الحروب والتضخم الاقتصادي والمؤثرات الأخرى، وهذا التوقع يدفع إلى توخي مصلحة هؤلاء الفقراء المقتضية إخراج الزكاة عن الحلي. رابعاً: الانفتاح المستقبلي للأموال إذا استمرت شريحة كبيرة بهذا الحجم بالشراء وتخزين الذهب بحجة لبسه؛ حتى لو الو

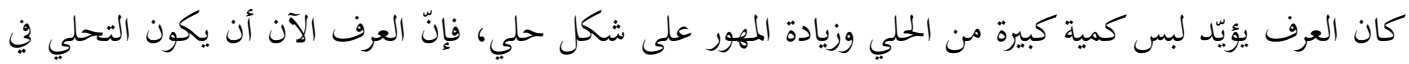

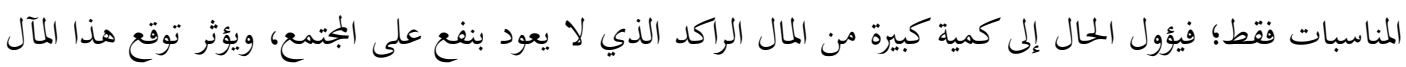

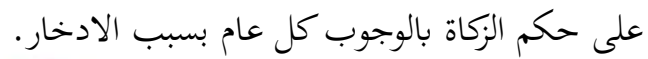

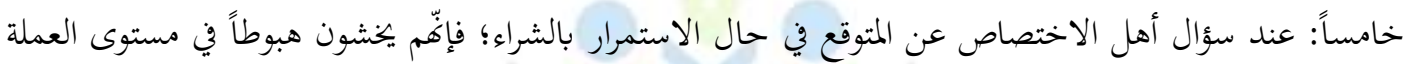

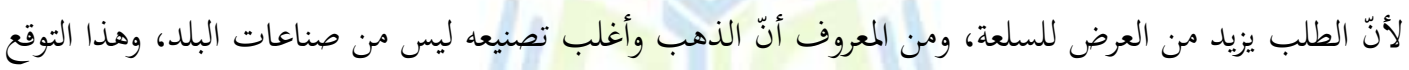

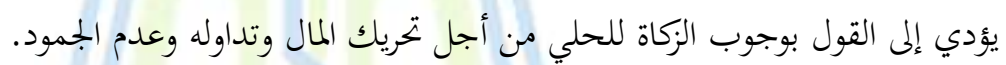

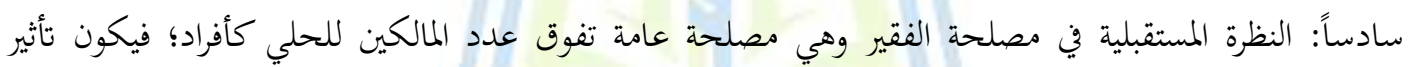
التوقع في أن تتقديم المصلحة العامة على الخاصة.

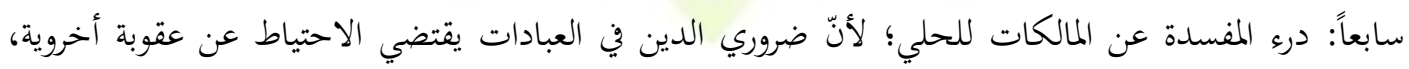

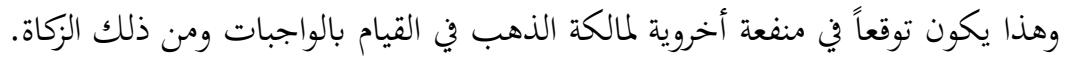

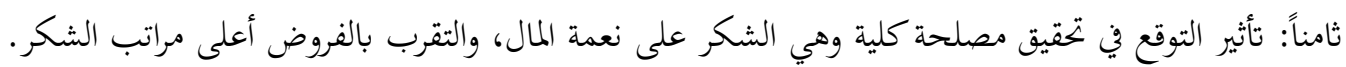

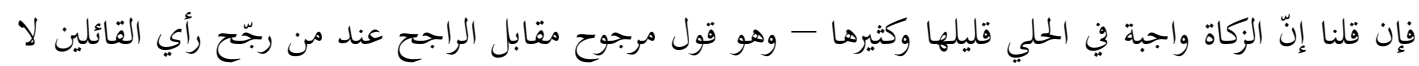

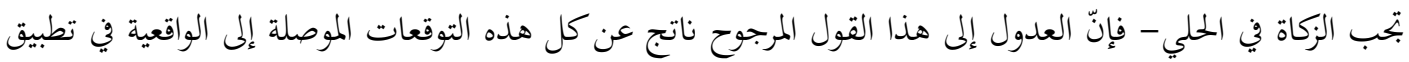

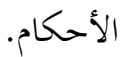


تاسعاً: التساوي في حكم(1) مقارنة النية أو طروء التغيير عليها بسبب الأحوال المتغيرة من الأمن إلى الحخوف، ومن

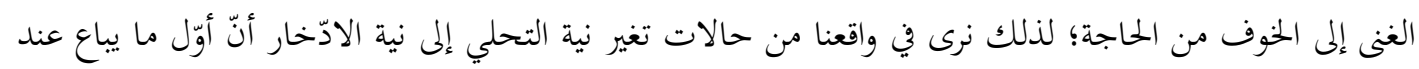

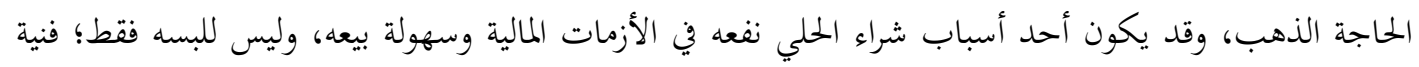

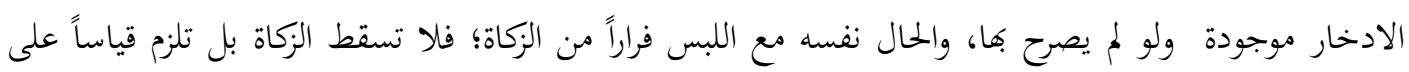

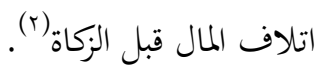
عاشراً: درء مفسدة الاسراف، حيث ان تعارض الادلة ودخول الاحتمال فيها جعل الجمع بينها أولى من الترجيح

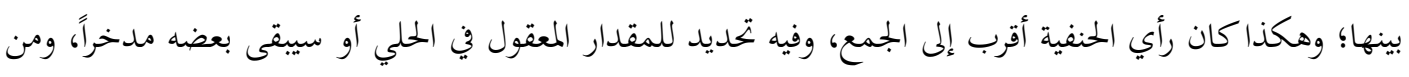

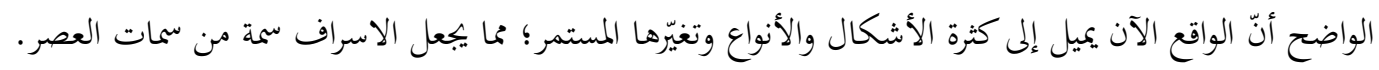

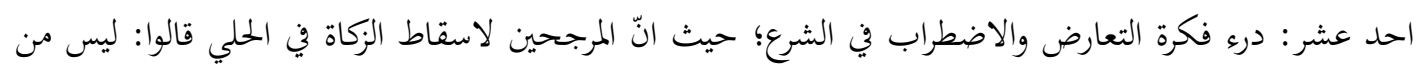

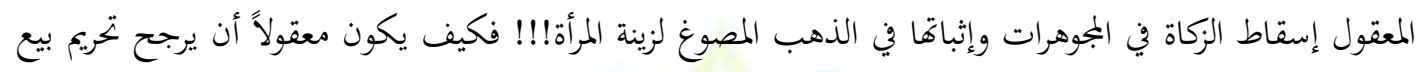

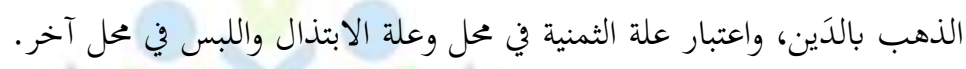

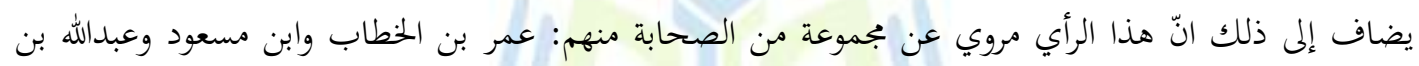

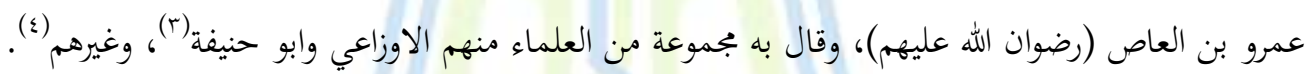

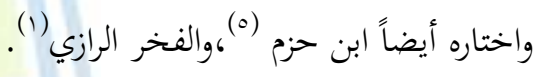

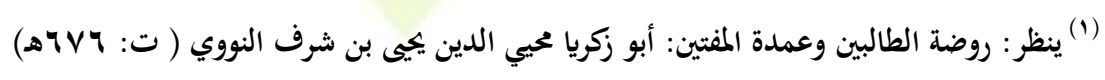

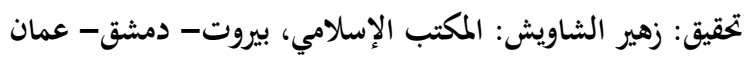

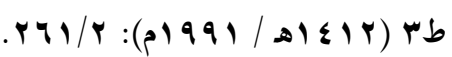

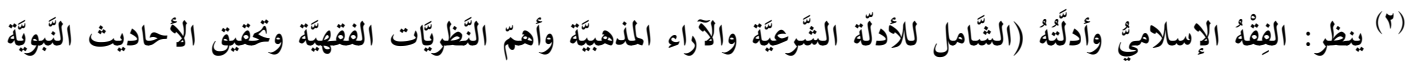

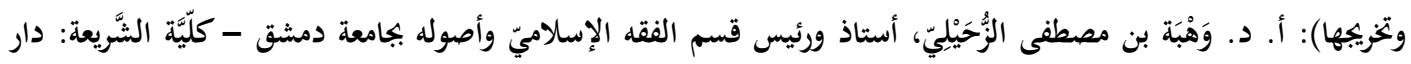

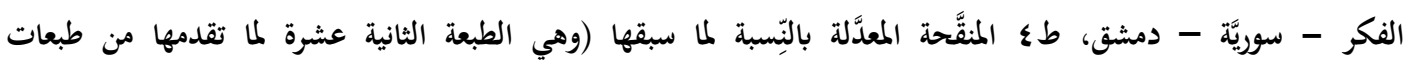

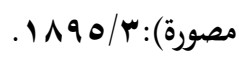

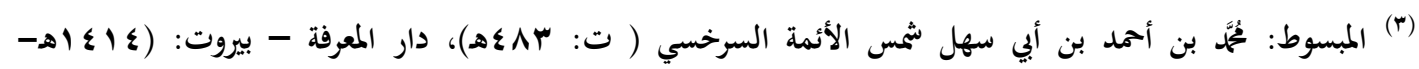
$194 / r:(p) 994$

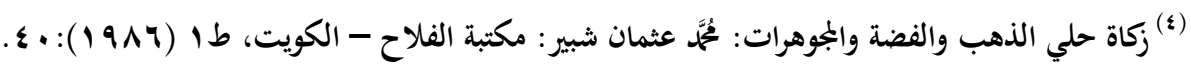

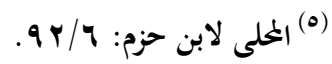

"T1 


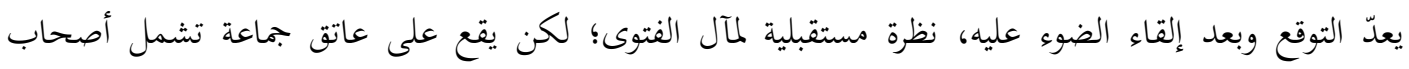

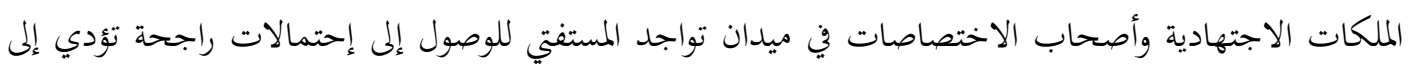
مصالح مققة.

لذلك يضمن الواقعية التي تؤدي إلى مواءمة حقيقية بين الواقع والمقاصد الشرعية.

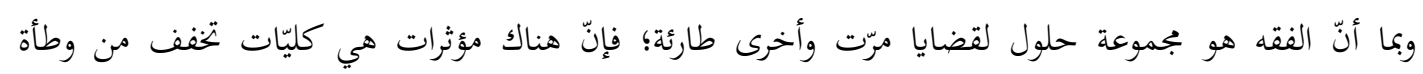

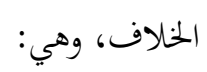
نصوص الشريعة ومقاصدها. تضاريس الزمان والمكان و تأئيرها على موازين الأعراف. مصالخ العباد.

فالتوقع هو أحد المراحل الأولية التي تكشف غاية الوصول ويتأسس علية تكييف المسألة الفقهي، ثيّ" معرفة البوابة

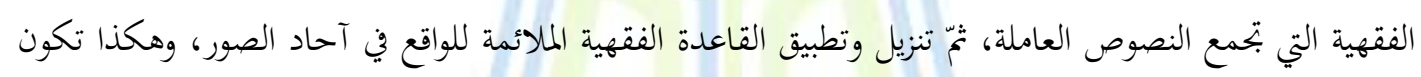
الواقعية إذا تطابقت تفاصيل الواقع مع التصور الذي كان مستقبليّا قبل التطبيق.

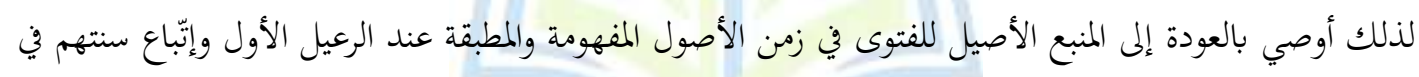

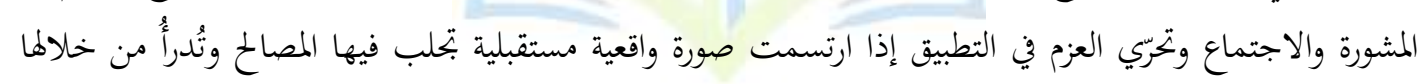

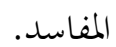

r.9

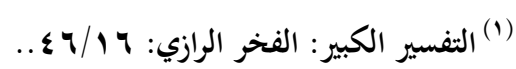




\section{المصادر

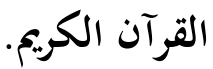

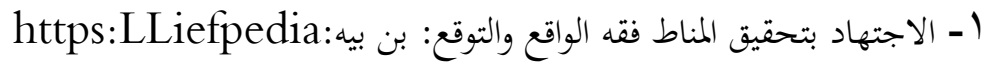

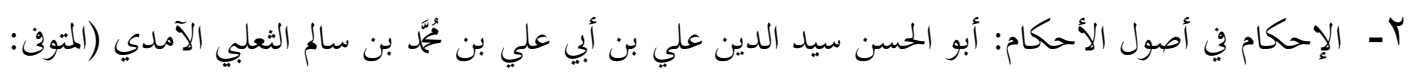

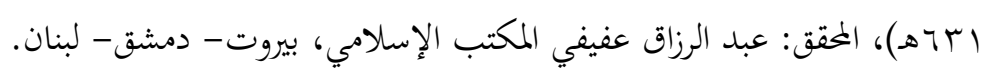

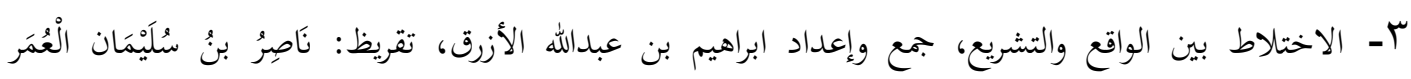

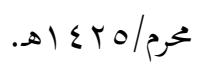

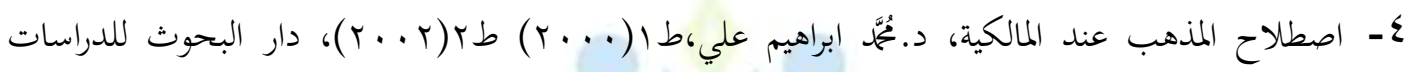

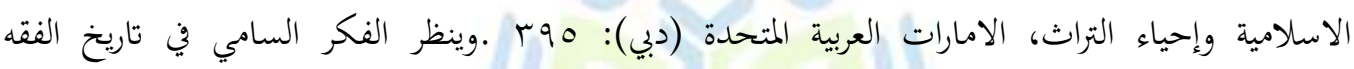

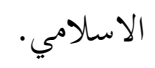

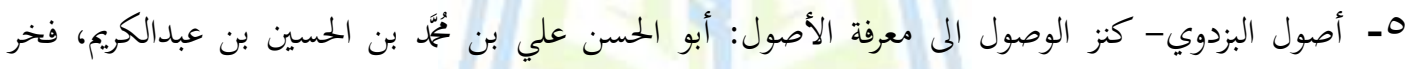

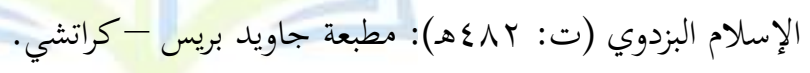

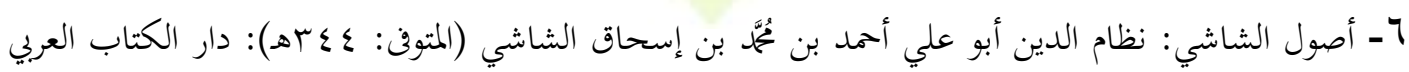

$$
\text { - بيروت. }
$$

V- إعلام الموقعين عن رب العلمين: ثُحَّة ايوب الملقب بابن قيم الجوزية، تخقيق: طه عبدالرؤوف سعد، دار الجيل

$$
\text { بيروت: (19Vr) (19). }
$$

人- أنوار التنزيل وأسرار التأويل: ناصر الدين أبو سعيد عبد الله بن عمر بن بمُحَّم الشيرازي البيضاوي (المتوف:

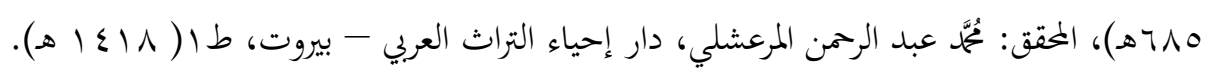

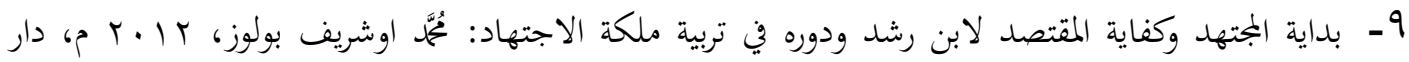

$$
\text { كنوز اشبيلية. }
$$

rv. 


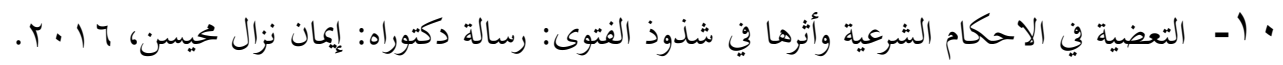
ا (1- التنبيه على مبادئ التوجيه-قسم العبادات: أبو الطاهر إبراهيم بن عبد الصمد بن بشير التنوخي المهدوي

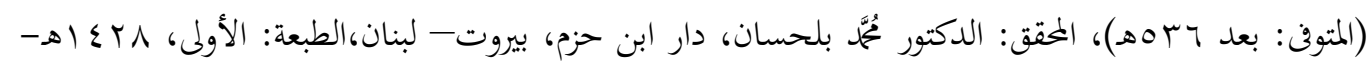

$$
\text { . PT. . V }
$$

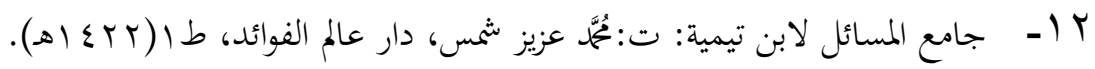

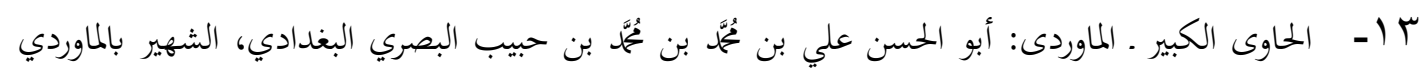

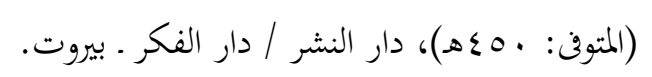

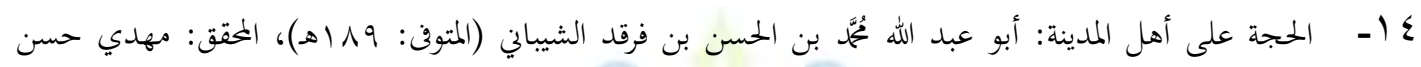

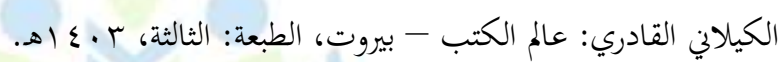

0 ا - رسالة في أصول الفقه، أبو علي الحسن بن شهاب بن الحسن بن علي بن شهاب العكبريّ الحنبلي (المتوفى:

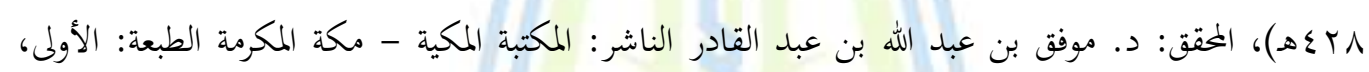
$.01994-81 \leqslant 14$ 7 ا - روضة الطالبين وعمدة المفتين: أبو زكريا محيي الدين يجيى بن شرف النووي (المتوفن: جلههـ)، تحقيق: زهير

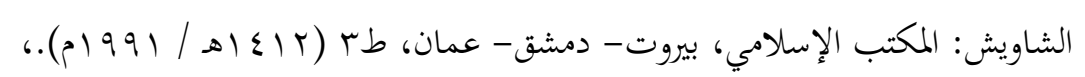

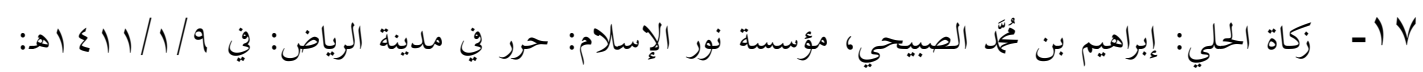
.www.islamlight.net 1 ا - الصحاح تاج اللغة وصحاح العربية: أبو نصر إسماعيل بن حماد الجوهري الفارابي (ت: بهوبه)، تحقيق:

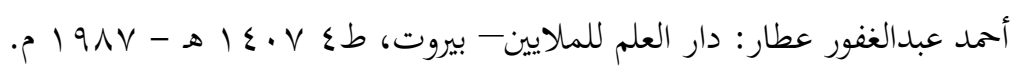
9 ا - العرف والعمل في المذهب المالكي: عمر عبدالكريم الجيدي. 


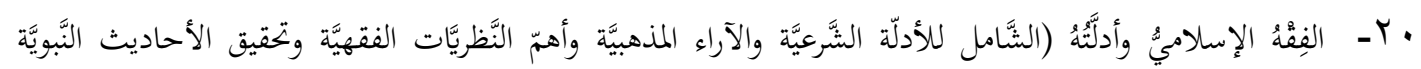

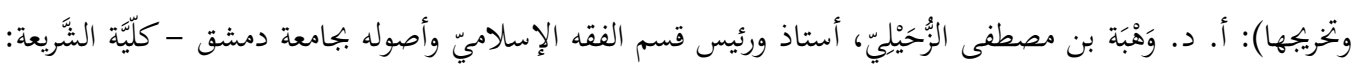
دار الفكر - سوريَّة - دمشق، ط؛ المنقَّحة المعدَّلة بالنِّبة لما سبقها (وهي الطبعة الثانية عشرة لما تقدمها من طبعات

$$
\text { مصورة). }
$$

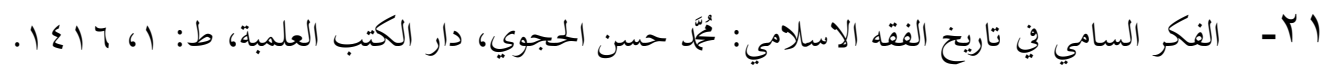
Y Y- قواطع الأدلة: منصور تُمَّمَ عبدالجبار السمعاني المروزي، ت (.77)، دار الكتب العلمية، بيروت. بr- قواعد الأحكام في مصالح الأنام: أبو يُمَّمَ عز الدين عبدالعزيز عبدالسلام بن أبي القاسم بن الحسن السلمي الدمشقي، (ت: . ـ7 هـ)، راجعه وعلق عليه: طه عبدالرؤوف سعد، مكتبة الكليات الأزهرية - القاهرة، طبعة: جديدة

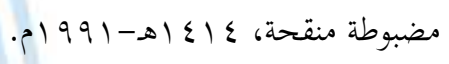

ع Y- لسان العرب: لمؤلف: مُحَّم بن مكرم بن على، أبو الفضل، جمال الدين ابن منظور الأنصاري الرويفعى

$$
\text { الإفريقى (المتوفن: 11 الهـ): دار صادر - بيروت: الطبعة: الثالثة - ع اع ا هـ. }
$$

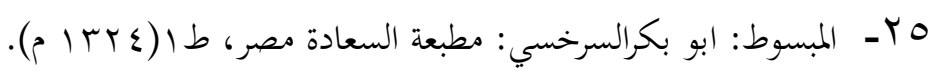

جr- المحصول: أبو عبد الله مُحّمَ بن عمر بن الحسن بن الحسين التيمي الرازي الملقب بفخر الدين الرازي خطيب

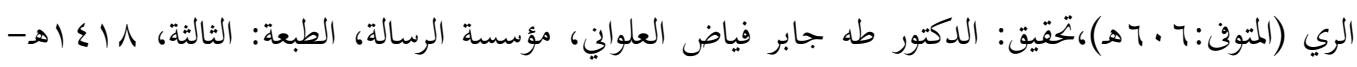


Published by the College of Islamic Sciences at the University of Fallujah

ISSN p.p:2708-3993 / ISSN o.I: 2708-4000

Vol;1- Issue;1/ (2020-2021))

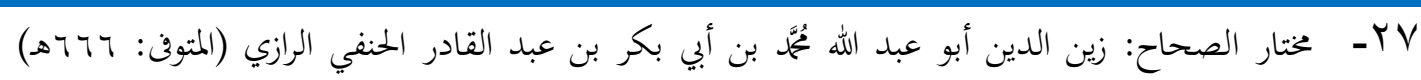

المحقق: يوسف الشيخ عُمَّ، المكتبة العصرية - الدار النموذجية، بيووت - صيدا، الطبعة: الخامسة، • بـ اهـ-

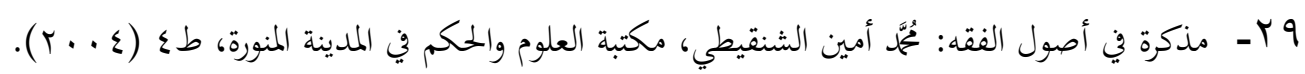
• ب- المستصفى في علم اصول الفقه: ابو حامد الغزالي، دار العلوم الحديثة، بيروت.

آT- معجم اللغة العربية المعاصرة: د. أحمد مختار عبد الحميد عمر (المتوف: ع ؟ع اهـ)بمساعدة فريق عمل:عالم

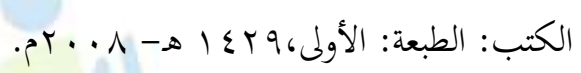

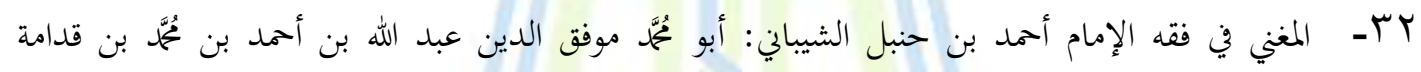
الجماعيلي المقدسي ثم الدمشقي الحنبلي، الشهير بابن قدامة المقدسي (المتوفن: • r7هـ): دار الفكر- بيروت،

$$
\text { الطبعة الأولى، ه. - مـ اهـ. }
$$

سT- المعجم الوسيط: مجمع اللغة العربية بالقاهرة، (إبراهيم مصطفى / أحمد الزيات / حامد عبد القادر / مُمَّم

$$
\text { النجار): دار الدعوة. }
$$

ع ז- مقالات موقع الألوكة:، بجموعة من العلماء والدعاة والمفكرين: العنوان: المستقبل للإسلام، رقم المقالة:

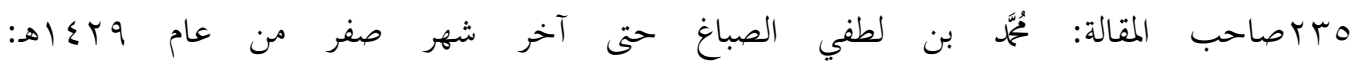
.http://www.alukah.net

rVT 
Published by the College of Islamic Sciences at the University of Fallujah ISSN p.p:2708-3993 / ISSN 0.l: 2708-4000

هب - الموافقات في اصول الشريعة: ابراهيم موسى الشاطبي، تحقيق حسن سلمان، دار المعرفة بيروت.

דب- نظرية المآلات وأثرها على مستجدات فقهية معاصرة دراسة في ضوء مقاصد الشريعة مقارنة بالقانون: عمر

$$
\text { عبد عباس. }
$$

V V- ظرية المقاصد عند لشاطبي: أحمد الريسوني، المعهد العلمي للفكر الاسلامي، الولايات المتحدة الامريكية .$(1990)$ 